\title{
ANÀLISI DE LA QUALITAT DE LA VEU DELS MESTRES D'EDUCACIÓ INFANTIL I PRIMÀRIA
}

\author{
Assumpció Segura Huguet \\ Departament d'Educació de la Generalitat de Catalunya \\ Edmon Elgström Misol \\ Universitat de Barcelona \\ edmon.elgstrom@ub.edu
}

\begin{abstract}
Resum
S'ha realitzat una anàlisi objectiva sobre el grau de salut vocal dels mestres d'educació infantil i primària que treballen en els centres públics de Catalunya. Les dades de l'estudi han estat analitzades i processades fent servir els paràmetres acústics de la qualitat vocal: Jitter, Schimmer i HNR. En conjunt, es detecta una clara presència de problemes de veu entre el col.lectiu docent (especialment, disfonia) que aconsella implantar una formació específica en els estudis de formació de mestres.
\end{abstract}

Paraules clau: veu, qualitat vocal, Jitter, Schimmer, HNR, docent

\section{Resumen}

Se ha realizado un análisis objetivo sobre el grado de salud vocal de los maestros de educación infantil y primaria que trabajan en los centros públicos de Catalunya. Los datos del estudio han sido analizados y procesados emplenado los parámetros acústicos de la calidad vocal: Jitter, Schimmer y HNR. En conjunto, se detecta una clara presencia de problemas de voz entre el colectivo docente (especialmente, disfonía) que aconseja implantar una formación específica en los estudios de formación de maestros.

Palabras clave: voz, calidad vocal, Jitter, Schimmer, HNR, docente

\begin{abstract}
An objective analysis has been carried out on the degree of vocal health of early chilhood and primary school teachers working in public centers in Catalonia. The study data have been analyzed and processed using the acoustic parameters of vocal quality: Jitter, Schimmer and HNR. Overall, a clear presence of voice problems (especially, dysphonia) is detected among the professional collective of teachers, that advises the implementation of specific training in teacher training.
\end{abstract}

Keywords: voice, voice quality, Jitter, Schimmer, HNR, teacher 


\section{INTRODUCCIÓ}

No podem oblidar que, entre d'altres coses, els mestres són un exemple de veu parlada i cantada pels seus alumnes, els quals copien els models presentats pels diferents mestres de l'escola. Per això, és imprescindible que les veus dels mestres siguin autènticament un model a imitar. Aquest aspecte implica que els mestres han d'assolir un grau de qualitat vocal considerable, tant pel mimetisme que duran a terme els seus alumnes (sobretot l'alumnat d'educació infantil i els primers cursos de primària), com per a la seva pròpia salut vocal. En aquest aspecte, val a dir que si els mestres coneixen el seu nivell de salut vocal i en tenen cura, a més del que significa per a ells mateixos, també representarà una millora pel seu alumnat, aspecte que es pot interpretar com una doble contribució de millora al sistema educatiu.

Tot i això, la mala salut vocal és un aspecte que es relaciona habitualment amb el col·lectiu de mestres, sent la causa de moltes baixes laborals. Sovint es parla d'una mala salut vocal del professorat $i$ es comenten xifres representatives de mestres afectats per problemes vocals. També es reivindica un increment de formació vocal, tant en la formació inicial dels mestres, com en la formació continuada dels mateixos, però realment no es disposa de xifres objectives que justifiquin científicament la necessitat d'incrementar l'existència de la formació vocal en el col·lectiu docent general, o bé en alguns grups específics de mestres.

Per tant, el que ara caldria fer és, en primer terme, analitzar objectivament la qualitat vocal dels mestres, per saber si les seves veus estan sanes, o bé si s'aprecia un inici cap a l'anormalitat en algun dels tres paràmetres més habituals que es valoren en analitzar les veus. Llavors, i amb les dades objectives de la salut vocal a la mà, poder dissenyar alternatives per corregir la situació existent, en funció a la realitat d'una població, d'una zona geogràfica, o de la totalitat del país.

En aquest aspecte, cal esmentar que existeixen tècniques i instrumental que permeten mesurar i conèixer objectivament la situació dels diferents paràmetres existents en la veu, aspectes que determinen el grau de qualitat vocal d'una persona. Es tracta de l'anàlisi acústic, el qual proporciona informació sobre la qualitat de la veu i de la funció vocal en un moment determinat, presentant l'avantatge de tractar-se d'una tècnica diagnòstica no invasiva.

Donat que la funció vocal és un fenomen multidimensional, qualsevol mesura simple de la veu obtindria una informació parcial de la funció vocal. Per tant, i segons les tendències actuals, l'anàlisi multidimensional dels diferents paràmetres acústics és la tècnica més acurada per analitzar l'estat de les veus, en aquest cas les dels mestres.

L'anàlisi acústic de la veu, juntament amb l'avaluació subjectiva per part del clínic experimentat, enriqueix el diagnòstic i guanya precisió, doncs es complementa amb les mesures objectives de paràmetres rellevants de la veu. D'altra banda, també cal esmentar com a avantatges de l'ús de l'anàlisi acústica de la veu, que tots els resultats i gràfics obtinguts poden ser arxivats i exportats a la major part dels softwares existents al mercat.

En definitiva, és per això, que és una bona raó el fet d'aplicar les tecnologies i el coneixement científic i tècnic a una problemàtica de la salut dels mestres per conèixer exactament quin és el grau de salut vocal d'un determinat col·lectiu. 
Atès que es tracta d'una recerca que pretén conèixer, d'una manera objectiva i mitjançant unes eines adients, l'estat de salut vocal concret dels mestres d'infantil i primària d'una població en concret, les contribucions al sistema educatiu seran diverses.

Així doncs, aquesta recerca es configura com un primer pas per tal de conscienciar als mestres d'una població en concret, de quina és la seva situació pel que fa a un dels aspectes de la salut laboral i, específicament, pel que respecta a la seva qualitat de veu. D'aquesta manera, es disposarà també de xifres objectives que permetran a l'administració, si n'és el cas, conèixer la necessitat d'organitzar cursos de formació vocal pels mestres en exercici, aspecte que contribuirà directament a reduir el nombre de baixes laborals per problemes de veu en els docents i, en definitiva, contribuir a la millora de la salut laboral dels mestres, especialment ajudant al professorat de nova incorporació en la seva tasca.

\subsection{Hipòtesi de la recerca.}

Els resultats de la recerca permetran conèixer, d'una manera totalment objectiva, l'alt índex de mala qualitat vocal dels mestres analitzats, el que, en conseqüència, significa mala salut vocal i, al mateix temps, una mala salut laboral. Igualment plantegem com a hipòtesi d'aquesta recerca la sorpresa que el coneixement de la informació suposarà per a molts dels mestres, ja que aquests ignoren que la seva veu està fora dels valors considerats com de normalitat. D'altra banda, i de ser la hipòtesi certa, es podria confirmar el fet que molts alumnes d'educació infantil i primària de la població de Castelldefels estan rebent uns models de veu a imitar que no són de bona qualitat per ser copiats.

\subsection{Objectius de la recerca}

La finalitat de la recerca ha consistit principalment en utilitzar els avenços científics $i$ tècnics per tal de conèixer el grau de salut vocal dels mestres de les escoles públiques de Castelldefels, a partir de dades objectives, tot realitzant un diagnòstic de la qualitat vocal dels mestres i, poder així advertir-los, en cas que n'hi hagi, de les problemàtiques existents. Aquesta recerca és del tot imprescindible com a pas previ per definir, concretar i demanar la necessitat de formació vocal en la formació inicial dels mestres, o bé en la formació permanent. Per tant, els objectius de la recerca es poden concretar en els següents:

- Realitzar una anàlisi objectiva de la qualitat de la veu dels mestres d'Educació Infantil i Primària, així com la dels mestres especialistes d'Educació Física, Música i Anglès; de la totalitat d'escoles públiques de la població de Castelldefels (Baix Llobregat).

- Dissenyar i aplicar diferents instruments per a la recollida de dades: el qüestionari de dades bàsiques, les gravacions individuals de veu $\mathrm{i}$ els seus protocols corresponents.

- Conèixer, amb dades objectives, la qualitat de la veu i el grau de salut vocal, dels esmentats docents, mitjançant la utilització d'un dels instruments més complets i utilitzats en l'anàlisi acústic de la veu per analitzar les dades obtingudes: el programa Praat.

- Conèixer de manera especial la situació de la qualitat de la veu dels mestres novells, donada la mancança de formació vocal en els estudis universitaris. 
- Informar a cadascun dels mestres integrants de la mostra dels resultats individuals obtinguts.

- Conscienciar als mestres d'Educació Infantil i Primària, així com als mestres especialistes de Música, d'Educació Física i d'Anglès de les escoles públiques de Castelldefels de la seva situació pel que fa a la qualitat de la veu, intervenint així en la millora de la salut vocal dels mestres de les esmentades escoles i, alhora, en els models vocals a prendre per l'alumnat.

- Presentar les dades obtingudes a l'administració corresponent, perquè pugui oferir alternatives per tal de pal·liar la situació de salut laboral.

- Intervenir en el disseny d'alternatives per corregir la situació existent en funció a la realitat d'una població en concert.

\section{ESTAT DE LA QUESTIÓ}

En aquest apartat, en primer lloc procedirem a definir la veu i a comentar les seves característiques principals, per posteriorment passar, i dins un terreny més específic, a comentar aspectes de la veu professional i de la salut vocal dels docents. Prosseguirà aquest estat de la qüestió realitzant un exhaustiu repàs, tant al principals estudis realitzats sobre la qualitat vocal dels docents, així com als programes i paràmetres utilitzats habitualment en l'anàlisi objectiva de la qualitat vocal.

\subsection{La veu: definició i característiques}

La veu es pot definir com el conjunt de sons que s'emeten gràcies a la interacció i coordinació de diferents aparells: el respiratori (pulmons, tràquea, nas i diafragma), el fonador (laringe i cordes vocals) i el ressonador (cavitat vocal, faringe, paladar i sinus maxil-lars i frontals). Cada veu té unes característiques diferents a les de qualsevol altre persona, les quals venen determinades pels següents paràmetres:

- El to o freqüència de la veu, que determina si les veus són greus o agudes. Es mesura mitjançant cicles per segon (hertz).

- La intensitat, que ens indica el volum fonatori en un determinat moment. Es mesura mitjançant decibels (dB).

- El timbre, que ens concreta les característiques pròpies de cada veu, les quals venen determinades per l'espectre harmònic de la mateixa. Aquest aspecte és el que ens permet diferenciar entre veus brillants, metàl·liques, apagades, etc.

A més a més, existeixen altres factors externs que influeixen en la producció vocal, com són la relaxació, la respiració, la posició, la postura, l'actitud, la ressonància i articulació, l'emissió, la fonació i la higiene vocal.

\subsection{Els docents com a professionals de la veu}

S'anomenen professionals de la veu aquelles persones que, donades les característiques de la seva professió, necessiten fer servir la veu per dur a terme la seva tasca. Aquest és el cas dels mestres, dels educadors, dels professors, dels actors, dels oradors, dels cantants, etc, i que, pel fet d'adreçar-se diàriament a grups de persones o a un públic força nombrós, necessiten disposar d'una correcta projecció de la seva veu per tal que aquesta pugui arribar correctament a la totalitat dels seus oients (Elgström, 2005: 83). 
La veu és una eina de treball pels docents i les exigències pròpies de l'exercici de la seva professió els fa enfrontar-se amb greus problemes vocals (fatiga vocal, disfonia, nòduls vocals, etc) que tenen el seu origen, fonamentalment, en un abús fonatori i en una defectuosa utilització de la veu. A tot això, s'han de sumar les causes que ho graven, com els factors ambientals a les aules, les condicions acústiques, així com la quantitat d'alumnes per aula. Doncs no podem oblidar, que els docents, en adreçar-se a un grup d'alumnes a l'interior de les aules o qualsevol lloc del centre docent, i a diferència d'una conversa amb pocs interlocutors en què es fa servir una veu col·loquial, els docents, en parlar, necessiten projectar la veu, activitat que requereix d'un bon domini de la veu.

D'altra banda, el docent és una figura model pels seus alumnes, els quals l'imiten, especialment en la seva manera de parlar. No es pot oblidar que el llenguatge oral s'adquireix per imitació i, conjuntament amb la seva família, el mestre és un dels agents crítics que tenen part en aquesta responsabilitat al desenvolupar, corregir i enriquir la comunicació, i com a part fonamental d'aquesta: la veu.

El fet que els docents desenvolupin la seva tasca sense el suficient coneixement de l'aparell fonador i de les característiques de la seva pròpia veu és preocupant, doncs implica que no poden desenvolupar la seva tasca com correspondria. Tal i com explica el otorrinolaringòleg Julian Preciado López, els docents haurien de rebre classes per, en primer lloc, treure-se'n el nerviosisme del professor novell provocat per el fet de parlar en públic, per saber com funciona l'aparell vocal i aprendre a fer-lo servir correctament.

\subsection{La salut vocal dels docents}

L'Organització Internacional del Treball (OIT) considera als docents com la primera categoria professional sota el risc de contraure malalties professionals de la veu, doncs el tipus de veu més propera a fer malbé els òrgans vocals és la veu projectada, és a dir la que es fa servir per a exercir una influència sobre d'altres persones.

Malgrat que des del 1966 l'OIT i l'Organització Mundial de la Salut (OMS) venen recomanant als països la vigilància de la salut vocal dels docents, segueixen existint dificultats pel reconeixement de les malalties professionals i els mestres són el col·lectiu que pateixen més problemes de veu, doncs les patologies de la veu tripliquen les d'altres professionals.

Le Huche, en Jackson-Menaldi (2002: 246), fa servir el terme disfonia funcional per designar els comportaments fonatoris que corresponen a un defecte d'adaptació i coordinació entre els diversos òrgans que participen en la producció de la veu i, que es caracteritzen, segons Bustos (2000:61), per la presència d'alteracions en alguna o vàries de les característiques acústiques bàsiques de la veu: l'altura, el timbre i la intensitat (Elgström, 2005: 84).

Les disfonies, les quals constitueixen un important capítol de la patologia foniàtrica, són processos patològics molt freqüents entre els professionals de la veu, especialment en l'ensenyament. Sent aquest col-lectiu un grup molt nombrós i tenint en compte la importat tasca social que desenvolupen en la formació de nens i joves, les difonies plantejaran importants problemes laborals, econòmics, socials i culturals en els docents.

En aquest aspecte, cal remarcar que la importància social de la disfonia en el personal docent no es deu únicament a les baixes laborals que ocasiona, amb el conseqüent trastorn 
que suposa un canvi de professor en l'aula, sinó també a que una veu disfònica ocasionarà una sensació d'inseguretat i una manca d'autoritat, una alteració de la personalitat i, moltes vegades, un aïllament del docent. Dins el concepte de disfonia podem distingir dues tipologies :

- Disfonia orgànica: en aquest tipus de disfonia, la causa del trastorn es una lesió dins de la laringe, la qual es troba de manera principal a les cordes o plecs vocals. Les lesions més habituals són la laringitis, quistes, edemes i pòlips.

- Disfonia funcional: en aquest tipus de disfonia la causa del trastorn no es troba de manera evident dins els components de la laringe, i entre ells les cordes vocals, sinó que es tracta d'una alteració de la veu que no està provocada per una lesió anatòmica dels òrgans fonatoris. Aquesta és el tipus de disfonia més habitual en els docents. Es produeix per:

- Un abús vocal: parlar molt, cridar, escurar excessivament la gola, tossir amb freqüència, inhalar pols o gasos, o bé cantar o parlar amb una tècnica inadequada.

- Un mal ús de la veu: parlar amb una intensitat i/o to més alt o diferent al que correspon a cada veu.

Els trastorns d'origen funcional que afecten al col·lectiu docent són, principalment, els nòduls. De fet, en el nostre país els nòduls de les cordes vocals, com a conseqüència dels esforços sostinguts de la veu per motius professionals, són l'única patologia reconeguda a l'actualitat com a malaltia professional en el col·lectiu docent.

D'altra banda, val a dir que l'estrès i la tensió que pateixen els docents influeix negativament en la veu, doncs a aquests els cal desenvolupar gran quantitat de tasques alhora, i això porta a generar una situació de nervis que provoca inseguretat i afecta al bon funcionament i a la coordinació dels diversos òrgans que intervenen en la producció de la veu, alterant-la.

Una vegada diagnosticada una disfonia funcional per un otorinolaringòleg o foniatra, les persones afectades han d'anar a la consulta d'un logopeda. El tractament es basa en reeducar la seva manera de parlar mitjançant la relaxació muscular, principalment del coll i de l'esquena, de la respiració (freqüència, intensitat i durada) i de la impostació, per treure el màxim profit de la seva veu.

Les diferents exploracions que s'han dut a terme per diagnosticar les alteracions de la veu dels docents han constituït un camp important per a la recerca de noves tècniques de valoració de la veu. Així doncs, tot seguit presentem els resultats del principals estudis realitzats a l'estat espanyol per conèixer la situació en què es troben les veus dels docents.

\subsection{Estudis realitzats sobre la qualitat vocal dels docents}

Un dels primer estudis realitzats per conèixer l'estat de salut vocal dels docents espanyols va ser el que va dur a terme Inés Aguinaga, l'any 1988, específicament amb 325 mestres de primària que treballaven a les escoles públiques de Pamplona. En aquest estudi es constatà que el $26.1 \%$ dels mestres participants presentaven alteracions faringolaríngies $\mathrm{i}$ disfonies, les quals en un 55,9\% estaven directament originades per la realització d'un esforç de la veu (Aguinaga,1988). 
D'ençà aquest estudi, la xifra de mestres amb mala salut vocal no s'ha reduït pas, sinó que, ans al contrari, ha anat en augment. Així ho demostren els treballs posteriors, com el que varen dur a terme Miguel Puyuelo i Maria Antònia Llinàs, l'any 1992, amb una mostra integrada per 790 mestres de 17 províncies de l'estat espanyol en què es conegué que en un $48 \%$ dels docents que constituïren la mostra hi havia problemes vocals (Puyuelo i Llinàs, 1992).

Tres anys més tard, a l'any 1995, María José Fiuza, publicà els resultats d'una recerca realitzada amb l'ànim de detectar la presència de disfonies entre els mestres de la Comunitat Autònoma Gallega, estudi en què van participar 760 mestres de les quatre províncies de la comunitat autònoma. Els resultats van evidenciar, un cop més, la presència de disfonies en un percentatge molt elevat, un 42,6\%, dels participants (Fiuza, 1995). Aquest mateix any, Urruticoetxea et al. (1995), ens informa que el 20,84\% d'un total de 1046 professors de l'ensenyament públics de Guipúscoa presentaren alguna patologia orgànica en l'exploració de la veu realitzada amb videolaringoestroboscòpia.

Un dels darrers estudis practicats, l'any 2005, és la recerca dirigida per Julián Preciado, en què es va practicar una anàlisi acústic i perceptiu de la veu, amb eines de medició objectives, a 905 docents (entre mestres i professorat de secundària) de la Comunitat Autònoma de La Rioja. Els resultats van evidenciar l'existència de trastorns vocals en un $57 \%$ dels docents estudiats, dels quals un $29 \%$ dels casos es va observar una disfonia de caràcter funcional (Preciado et al. 2005).

En definitiva, podem concloure que els estudis científics practicats a docents de l'estat espanyol per tal de conèixer les problemàtiques vocals, separats entre ells per disset anys, evidencien un alt índex de problemes vocals entre el col·lectiu com a conseqüència d'un mal ús de la veu i, alhora, demostren que el nivell de coneixements del col·lectiu docent en temes de formació vocal no és encara el que hauria de ser (Elgström, 2009).

\subsection{Principals programes i paràmetres utilitzats en l'anàlisi objectiva de la qualitat vocal}

L'anàlisi acústic de la veu ha assolit un important desenvolupament en els últims temps, gràcies, entre d'altres raons, al progrés i a la difusió experimentats pels mitjans informàtics que el fan possible. Entre els seus avantatges destaca el seu mètode no invasiu d'avaluació de la veu i el fet d'oferir l'oportunitat d'objectivitzar l'avaluació en uns paràmetres numèrics, aspecte que ens permet mesurar i conèixer objectivament el grau de qualitat d'una veu en un moment determinat.

Entre els principals programes utilitzats habitualment per dur a terme l'anàlisi objectiva de la qualitat vocal en destaquem dos: el Multi-Dimensional Voice Program (MDVP) i el Praat. Pel que fa al Multi-Dimensional Voice Program (MDVP), val a dir que fou el primer en crear-se. Aquest sistema calcula fins a un total de 33 mesures de la funció vocal, les quals pertanyen a diferents dimensions i les representa gràficament en relació a valors normatius que el programa incorpora. 


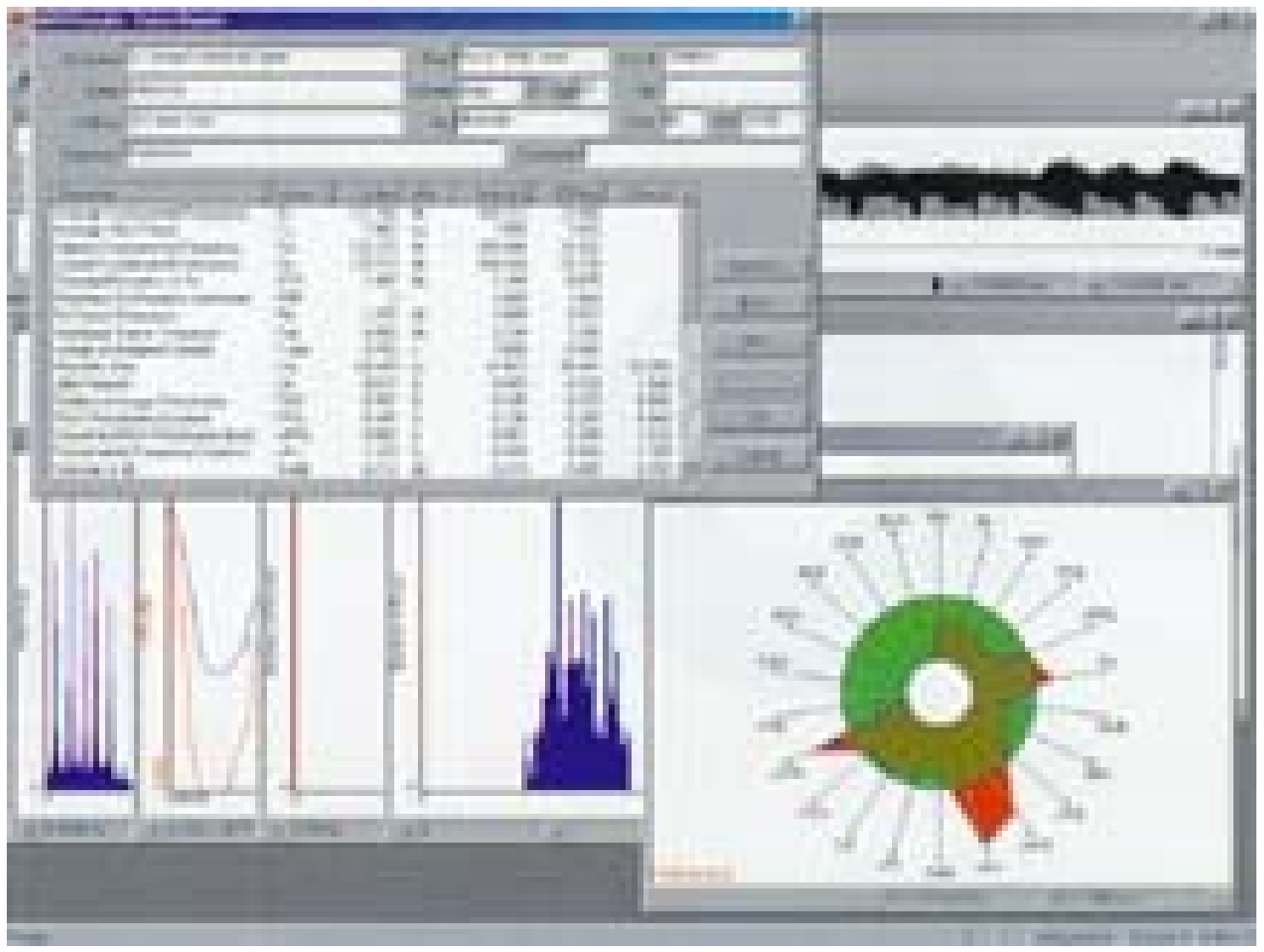

Figura 1 - Imatge que mostra el resultat d'un anàlisi de veu en el programa Multi-Dimensional Voice Program (MDVP)

Mitjançant aquesta representació es visualitza la significació clínica d'un ampli conjunt de paràmetres, gran part dels quals són d'ús standard en l'anàlisi clínic de la veu. MDVP és un software científic, de caràcter comercial, que funciona amb el hardware CSL 4500 (Computerized Speech Lab).

D'altra banda, el Praat és el programa d'anàlisi acústica i aplicacions en tecnologies de la veu, de caràcter científic, que es pot descarregar gratuïtament de la xarxa d'internet, i que està contínuament en procés d'actualització, cosa que permet sempre tenir la darrera versió existent. Actualment, Praat (versió. 5.0) és l'estàndard en anàlisi acústica per la solidesa de les seves mesures i per la flexibilitat del sistema. A les seves darreres versions s'han incorporat algoritmes què permeten l'anàlisi de la qualitat vocal. Val a dir que aquest programa ofereix menys dades que el Multi-Dimensional Voice Program (MDVP), ara bé, es pot dir que estan més acurades. 


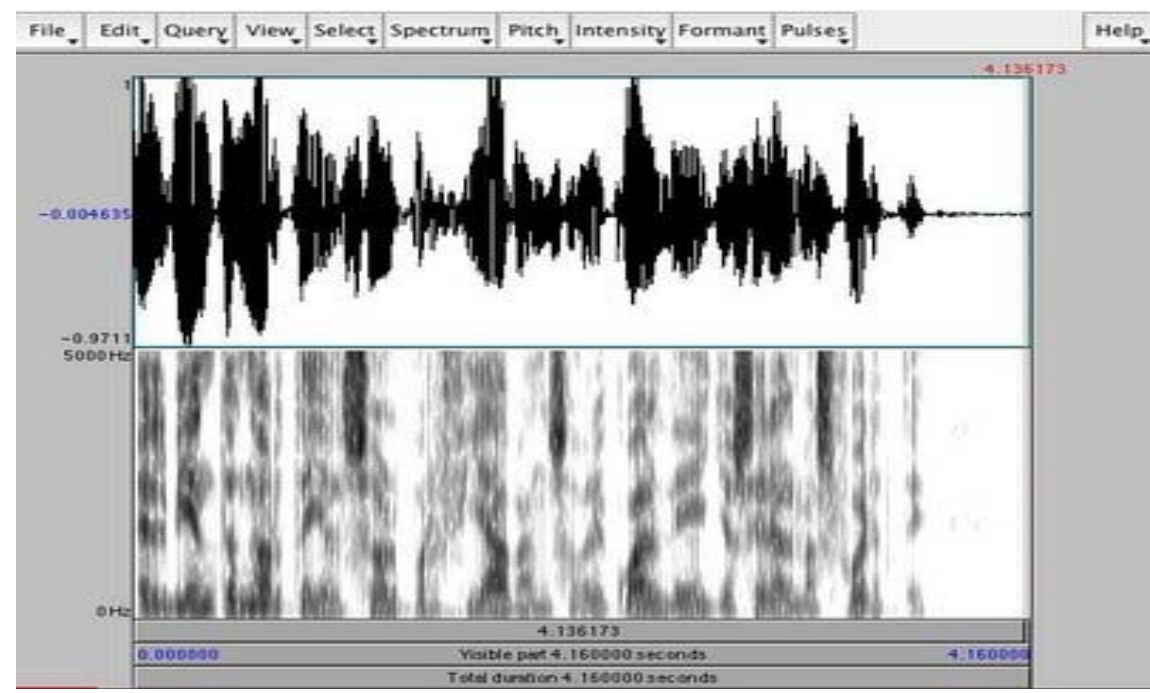

Figura 2 - Imatge que mostra el resultat d'un anàlisi de veu en el programa Praat

\begin{tabular}{|l|}
\hline Pitch: \\
\hline Median pitch: $129.690 \mathrm{~Hz}$ \\
\hline Mean pitch: $129.658 \mathrm{~Hz}$ \\
\hline Standard deviation: $1.579 \mathrm{~Hz}$ \\
\hline Minimum pitch: $126.332 \mathrm{~Hz}$ \\
\hline Maximum pitch: $133.871 \mathrm{~Hz}$ \\
\hline Pulses: \\
\hline Number of pulses: 1563 \\
\hline Number of periods: 1562 \\
\hline Mean period: $7.710223 \mathrm{E}-3$ seconds \\
\hline Standard deviation of period: $0.108612 \mathrm{E}-3$ seconds \\
\hline Voicing: \\
\hline Fraction of locally unvoiced frames: $0 \quad(0 / 1203)$ \\
\hline Number of voice breaks: 0 \\
\hline Degree of voice breaks: 0 (0 seconds / 12.069750 seconds) \\
\hline Jitter: \\
\hline Jitter (local): $0.318 \%$ \\
\hline Jitter (local, absolute): $24.505 \mathrm{E}-6$ seconds \\
\hline Jitter (rap): $0.156 \%$ \\
\hline Jitter (ppq5): $0.195 \%$ \\
\hline Jitter (ddp): $0.468 \%$ \\
\hline Shimmer: \\
\hline Shimmer (local): $6.932 \%$ \\
\hline Shimmer (local, dB): 0.667 dB \\
\hline Shimmer (apq3): $3.660 \%$ \\
\hline Shimmer (apq5): $4.212 \%$ \\
\hline Shimmer (apq11): $5.373 \%$ \\
\hline Shimmer (dda): $10.981 \%$ \\
\hline Harmonicity of the voiced parts only: \\
\hline Mean autocorrelation: 0.940260 \\
\hline Mean noise-to-harmonics ratio: 0.070421 \\
\hline Mean harmonics-to-noise ratio: $13.448 \mathrm{~dB}$ \\
\hline
\end{tabular}

Taula 1 - Diferents valors d'un anàlisi de veu realitzat amb el programa Praat. 
En qualsevol programa d'anàlisi acústica objectiva de la veu, els paràmetres principals, utilitzats per conèixer la qualitat d'una veu determinada, són tres: Jitter, Shimmer i Harmonics-to-Noise Ratio (HNR). En cadascun d'aquest paràmetres es calculen diferents mesures que poden presentar resultats totals, anomenats com a local (Jitter local, Schimmer local....) i valors parcials que analitzen diferents períodes consecutius aïllats de l'emissió de la vocal analitzada.

El Jitter és un paràmetre de la veu molt utilitzat que mesura el grau en què els cicles són diferents entre si pel que fa a la seva durada, o període. Si els cicles fossin idèntics els uns als altres, el Jitter seria zero. Això no passa mai en la veu humana, on sempre hi ha petites variacions d'un cicle a un altre. No obstant això, les variacions són tan petites que el Jitter es mesura en microsegons, o milionèsimes de segon. La diferència entre les veus sanes $i$ les patològiques per diverses etiologies (malalties neurològiques, pòlips, nòduls, tumors, paràlisi d'una corda vocal, etcètera) és que les darreres solen tenir Jitters alts perquè els cicles són molt diferents entre si, a conseqüència de les irregularitats de vibració de les cordes vocals.

Tècnicament, el Jitter és la mitjana de les diferències entre els períodes mesurats cicle a cicle. Es calcula de manera semiautomàtica mitjançant un software específic a partir d'una mostra de veu que consisteix en la fonació sostinguda d'una vocal, habitualment la "a", durant 1.5 a 3 segons. Hi ha diverses versions del Jitter que consisteixen en calcular les diferències, no cicle a cicle, sinó entre grups de cicles consecutius. Depenent del nombre de cicles s'obtenen diferents paràmetres que mesuren trets específics de la veu. El llindar de normalitat de Jitter local es situa, com a màxim, en el 1,04\% i es calcula a partir de la informació del to extreta període a període.

El segon paràmetre que es fa servir en els programes d'anàlisi acústica objectiva de la veu és el Shimmer, que seria equivalent al Jitter, però aquesta vegada en relació a l'amplitud del cicle, en lloc de la seva durada. Es calcula a partir de l'amplitud màxima de cada cicle, mesura pic a pic, o distància entre el pic positiu més alt i el negatiu més baix. Dóna una idea del grau de disparitat que existeix entre les amplituds dels cicles consecutius. Així doncs, si tots els cicles fossin iguals, el Shimmer seria 0 i la veu sonaria poc natural. Les veus humanes sempre tenen petites variacions entre les amplituds dels seus cicles que donen lloc a valors de Shimmer superiors a zero. El valor que es considera com a límit superior de normalitat se situa sobre 3,810\%, o dit d'altra manera al voltant del $4 \%$ de l'amplitud total d'un cicle (Deliyski, 1993). Per la qual cosa es diu que les veus patològiques tendeixen a sobrepassar aquests llindars.

També el Shimmer presenta diverses versions si les diferències es calculen, en comptes de cicle a cicle, fent la mitjana de grups de cicles consecutius. Val a dir que, donada la gran variabilitat que la veu humana presenta de manera natural, aquests paràmetres també estan sotmesos a grans variacions dins de la normalitat. El diagnòstic d'una veu patològica sempre és aproximatiu i guanya pes quan són diversos els paràmetres que conflueixen en valors anormals.

El tercer paràmetre utilitzat en l'anàlisi objectiva de la qualitat vocal és el HNR harmonics-to-noise ratio, és a dir la relació que existeix entre el soroll i els harmònics que hi ha en un so, la qual es registra en decibels $(\mathrm{dB})$. Aquest paràmetre fa referència al soroll entre els harmònics, el qual està associat al tancament incomplet del les cordes vocals i a 
la variació de la freqüència en el Jitter i de l'amplitud en el Schimmer. Un augment d'aquest índex s'interpreta com a un increment espectral del soroll.

Els paràmetres basats en la relació que hi ha entre l'energia harmònica i l'energia de soroll tenen una àmplia aplicació en la clínica de la veu, donada la directa relació amb moltes disfonies. D'altra banda, val a dir que són unes dades molt sensibles als sistemes de registre que es fan servir per a la recollida de dades, donat que aquests poden introduir nivells de soroll aliens als de la pròpia veu, alterant així els resultats, per la qual cosa és molt important recollir les dades en espais que puguin estar aïllats de qualsevol mena soroll.

Una veu amb qualitat vocal té un HNR al voltant dels $20 \mathrm{~dB}$ i quan més qualitat té la veu més supera a l'alça aquest valor. Pel contrari, quan més baix és el valor resultant de l'anàlisi, més quantitat de soroll hi ha en la veu i pitjor qualitat vocal presenta aquesta.

\section{DESCRIPCIÓ DEL PROCÉS}

En aquest tercer capítol es realitza una descripció del procés dut a terme. Per això, en primer lloc, i després de comentar la metodologia triada per desenvolupar la recerca, s'inicia la descripció de l'acció amb els aspectes relatius a la mostra de l'estudi (criteris per a la selecció i la tria de participants, codificacions assignades...). Tot seguit es dur a terme una descripció dels instruments d'anàlisi per a la recollida de dades, fent esment als aspectes relatius a la validació i aplicació dels mateixos, així com del protocol d'anàlisi per a la recollida de dades.

\subsection{Metodologia triada per desenvolupar la recerca}

La metodologia triada per dur a terme aquesta recerca és de caràcter quasi experimental. Està composada per una part de caràcter més qualitatiu, l'entrevista, i una altra de quantitativa, la lectura del text i la prova de veu amb la vocal "a" mantinguda. Especialment, val a dir que en aquestes darreres, només un metodologia de caràcter quantitatiu ens pot ajudar a obtenir dades i percentatges dels paràmetres que els mestres poden tenir alterats.

\subsection{Descripció de l'acció}

La tercera setmana del mes de setembre de 2008, i en tan bon punt les escoles ja portaven a terme la seva activitat lectiva d'una manera estabilitzada després de la tornada a les aules, es va contactar amb els equips directius dels deu centres de titularitat pública de Castelldefels, és a dir, la totalitat d'escoles públiques de la població, les quals varen comprometre's el mes d'abril de 2008, mitjançant un escrit signat pels seus directors, a participar en el projecte de recerca.

Les escoles participants (ordenades alfabèticament) han estat:

- CEIP Antoni Gaudí

- CEIP Can Roca

- CEIP Edumar

- CEIP Els Pins

- CEIP Garigot
- CEIP Jacint Verdaguer

- CEIP Josep Guinovart

- CEIP Lluís Vives

- CEIP Margalló

- CEIP Torre Barona 
Un cop es parlà amb els equips directius de la totalitat dels centres, es procedí a exposar a tots el claustres, mitjançant una circular informativa (inclosa a l'Annex I d'aquest informe), la tipologia de l'estudi a desenvolupar i les característiques que havien d'acomplir les persones interessades en participar de cada centre, és a dir, la mostra de l'estudi.

\subsubsection{Selecció de la mostra}

Per tal de disposar d'una mostra àmpliament representativa, la qual donés fiabilitat a les dades resultants, es va pensar en que aquesta fóra integrada per set mestres de cada centre educatiu de titularitat pública de la població, 70 mestres en total. Aquestes set persones estarien triades a cada centre entre les següents especialitats:

- Dos mestres d'educació infantil

- Dos mestres d'educació primària

- Un mestre especialista de música

- Un mestre especialista d'educació física

- Un mestre especialista d'anglès

\subsubsection{Criteris per a la tria de participants de la mostra}

Els criteris que es van aplicar per poder portar a terme la selecció dels mestres participants en la mostra de la recerca practicada van estar els següents:

En els cas dels mestres d'educació infantil i d'educació primària es trià entre el mestre més novell, o en el seu defecte aquell que portava menys anys treballant com a mestre, entre els interessats a participar en l'estudi. D'altra banda, l'altre mestre a triar fou aquell que portava més anys continuats treballant com a docent. En el cas dels mestres especialistes de música, d'educació física i d'anglès, en cas d'haver-ne dos o més es trià el mestre que impartia més hores de docència al centre $i$, en igualtat de condicions, el mestre més novell.

Un cop es varen recollir les diferents sol·licituds de participació en l'estudi a la totalitat de centres de Castelldefels, es va procedir a triar definitivament als integrants de la mostra entre els diferents mestres que estaven interessats, tot aplicant els criteris anteriorment descrits. Un cop triada la mostra, es va contactar en els dies següents, i a títol individual, amb els mestres que finalment integraren la mostra, per tal de donar-los les gracies per la seva predisposició i interès a participar en la recerca. Val a dir que la quantitat de mestres interessats en participar en l'estudi va superar les places disponibles que integraven la mostra.

\subsubsection{Codificació de la mostra}

Així doncs, i per tal de protegir la identitat dels mestres participants en la recerca s'ha procedit a adjudicar una codificació a cadascuna de les persones participants. La codificació es va realitzar abans del inici de les diferents proves, i sempre en funció als següent paràmetres: el centre de treball i el codi de gravació. Pel que fa al centre de treball, les escoles han estat ordenades seguint el criteri alfabètic (de la A a la J). 


\subsection{Descripció dels instruments d'anàlisi per a la recollida de dades: validació i aplicació}

Alhora que es seleccionava i codificada la mostra de mestres participants, el mes d'octubre de 2008, es va procedir a dissenyar definitivament els tres instruments d'anàlisi per a recollida de dades, juntament amb el seu corresponent protocol d'aplicació, els quals han estat elaborats específicament per dur a terme aquest recerca. El primer instrument ha consistit en una entrevista oberta, el segon i el tercer han estat un enregistrament de la veu dels participants de dues maneres diferents: llegint un text i emetent vocals sostingudes.

Val a dir que en una fase preliminar, desenvolupada el més d'octubre de 2008 es van validar els tres instruments d'anàlisi creats en ser aplicades a un grup de cinc persones per tal de comprovar la solidesa i l'efectivitat del seu disseny, al mateix temps que es va realitzar un treball experimental en la utilització del programa d'anàlisi acústica de la veu triat per a la recerca: el Praat.

\subsubsection{Entrevista oberta}

El primer instrument ha consistit en la realització d'una entrevista oberta, però dirigida, en la qual els mestres han respost en parla espontània, la qual ha tingut una durada aproximada d'uns tres minuts, $i$ que ha estat enregistrada en un gravadora digital. Per aquesta prova s'ha establert un protocol de preguntes que es demanen als mestres participants en l'estudi:

- Edat

- Sexe

- Especialitat que imparteixen a l'escola

- Quants anys fa que treballa com a mestre/a

- Experiències sobre la seva formació vocal

- Existència d'alguna patologia o problemàtica vocal diagnosticada

- Consciencia de tenir problemes vocals

- Prevenció de mesures d'higiene vocal

- Participació, en l'actualitat, cantant en alguna coral

\subsubsection{Enregistrament de la veu (text)}

El segon instrument de recollida de dades va consistir en la lectura en veu alta d'un petit fragment de text, igual per a tothom i que, amb una durada aproximada d'un minut, ha estat, igualment enregistrat en la gravadora digital. El text triat per la lectura va consistir en un petit fragment que pertany a "El Petit Princep" de l'escriptor francès Antoine de Saint-Exupéry, el qual mostrem tot seguit:

El cinquè planeta era molt curiós. Era el més petit de tots. Només hi cabien un fanal i un fanaler. El petit príncep no acabava d'explicar-se de què podien servir, en un lloc perdut en el cel, en un planeta sense cap casa ni cap vila, un fanal i un fanaler. 


\subsubsection{Enregistrament de la veu (vocals)}

El tercer instrument ha consistit en recollir una mostra de veu a partir de l'emissió de la vocal "a" sostinguda, en dos moments diferents. Les mostres van consistir en dos registres consecutius, espaiats entre si per uns segons de descans, de la fonació sostinguda de la vocal "a". La primera emissió va tenir una durant de només cinc segons, mentre que en la segona es va emetre la mateixa vocal fins que a l'informant se li acabés l'aire.

Ambdues proves han estat enregistrades en un gravadora digital d'alta definició. Val a dir que tant el segon instrument aplicat en aquesta recerca, la lectura en veu alta d'un petit fragment de text, com el tercer instrument han estat aplicats seguint un protocol d'anàlisi el qual es troba descrit detalladament tot seguit.

\subsection{Descripció i aplicació del protocol d'anàlisi per a la recollida de dades}

Donat que el protocol d'anàlisi és, sens cap mena de dubte, un dels aspectes considerats com a imprescindible a tenir en compte per poder considerar com a fiables les dades obtingudes al llarg de cada medició, en aquesta recerca s'ha elaborat un protocol d'anàlisi, què ha estat aplicat rigorosament per a cadascuna de les diferents medició efectuades, $\mathrm{i}$ que consta dels següents aspectes:

\subsubsection{Horari de realització}

Les proves de veu es van dur a terme, per a tots els participants en la recerca, d'una manera idèntica, és a dir, sempre el mateix dia de la setmana i en la mateixa franja horària: els dimarts dels mesos d'octubre, i novembre de les 13 a les 14 hores. D'aquesta manera tots els participants van ser analitzats el mateix dia de la setmana i a la mateixa franja horària. Aquest aspecte va permetre que tots els mestres analitzats estiguessin en idèntiques condicions vocals.

\subsubsection{Espai de realització}

Per tal de que fóra possible aconseguir una alta participació dels mestres en l'estudi es va optar, en comptes que els mestres explorats assistissin al Laboratori de Fonètica Aplicada de la Universitat de Barcelona, per recollir les dades en els seus respectius centres de treball. Per això es va demanar a la direcció dels centres educatius poder disposar d'una sala o despatx en què hagués silenci per tal que cap soroll que provingués de l'exterior pogués interferir en les tasques de medició de la veu.

\subsubsection{Gravació: calibració i ajustament}

La gravació es va portar a terme mitjançant una gravadora digital d'alta definició que incorporava un micròfon, el qual ha estat posat a una distància aproximada de uns 20 centímetres dels llavis de l'informant i un angle de 45 graus. Abans d'iniciar les diferents sessions de medició -i sense informants al davant- es va realitzar un repàs del funcionament de l'equip de gravació, així com l'ajustament dels seus diferents volums, calibrats exactament igual per a cada medició. A més, es va realitzar a cada centre una gravació de mostra per comprovar que la sala assignada a cada escola per dur a terme l'enregistrament estava realment lliure de sorolls. 


\subsubsection{Comunicació de les instruccions bàsiques}

Un aspecte imprescindible del protocol d'anàlisi, en aquest cas per a les medicions de la veu, consisteix en la transmissió, a les diferents persones explorades, de les instruccions bàsiques del funcionament de les gravacions, prèviament a la seva aplicació, donat que és una de les causes que influeix directament en la variació dels resultats d'aquesta prova, juntament amb la motivació i la pràctica. Les esmentades normes bàsiques del funcionament de la prova, a més d'una breu però detallada descripció del procés de medició que es desenvolupava, fan referència a quan i com emetre cada so, sobre quina és la postura corporal a adoptar durant la medició i la distància a mantenir entre la boca $\mathrm{i}$ el micròfon a llarg de la medició.

\section{TRACTAMENT I ANÀLISI DE LES DADES OBTINGUDES}

En aquest quart capítol de la recerca, en primer lloc es comenten els aspectes que han estat establerts per seleccionar les dades recollides abans de procedir al seu anàlisi. Posteriorment, es realitza una descripció de com han estat processades les mateixes, alhora que es comenten aspectes dels tres paràmetres més habituals, els quals han estat aplicats a les dades seleccionades i tractades, per conèixer la qualitat de les veus estudiades. Finalment, es presenten diverses consideracions respecte als valors normals, o standards, a partir dels quals es procedeix a determinar la situació de cadascuna de les veus analitzades.

\subsection{Selecció de les dades a processar}

Després que la veu de cada subjecte va ser gravada individualment, tal i com s'ha especificat en la descripció del segon i del tercer instrument de recollida de dades, es va descartar l'enregistrament de veu llegint el text per ser analitzat i obtenir dades relatives a la qualitat vocal dels components de la mostra. El motiu ha estat que l'esmentada lectura ha constituït, des del principi de la recerca, una preparació encoberta perquè, un cop els informants estiguessin familiaritzats amb l'instrument d'obtenció de les dades, poguessin oferir una vocal "a" de qualitat, sent el màxim de semblant a la realitat vocal de cada informant. Per tant, l'enregistrament realitzat de l'emissió de la vocal "a", que es va dur a terme posteriorment a la lectura del text, és el que s'ha pres realment com a referència pel posterior anàlisi dels paràmetres que configuren l'anàlisi objectiva de la qualitat vocal dels subjectes estudiats.

Pel que fa al programa utilitzat per analitzar les dades recollides, tot i que en el projecte inicial de recerca es plantejava l'anàlisi dels fragments sonors fent servir els dos principals programes informàtics d'anàlisi acústic, MDVP i Praat; finalment s'ha optat per només utilitzar un dels dos programes. S'ha pres aquesta decisió donat que en una comparació clínica entre aquests dos programes informàtics feta per Amir et al. (2008), s'ha demostrat que, tot $\mathrm{i}$ que es troben altes correlacions entre els valors obtinguts per ambdós programes, la combinació dels resultats d'aquests no és aconsellable, per tant l'anàlisi que s'efectua a les mostres de veu dels mestres participants en la recerca ha estat utilitzant únicament el programa Praat.

\subsection{Tractament de les dades obtingudes amb el programa d'anàlisi de la veu Praat}


Tal i com ja ha estat comentat en el capítol segon, un dels programes per dur a terme l'anàlisi objectiva de la qualitat vocal és el programa Praat. Es tracta d'un programa d'anàlisi acústica i aplicacions en tecnologies de la veu, de caràcter científic, que permet l'anàlisi dels principals paràmetres acústics vocals, com són: el Jitter, el Schimmer i el NHR. Actualment, Praat (versió. 5.0), és l'estàndard en anàlisi acústica per la solidesa de les seves mesures, per la flexibilitat del sistema i per la fiabilitat dels resultats, aspecte que permet confiar en l'estabilitat dels valors obtinguts.

En aquest aspecte val a dir que, en l'extracció de paràmetres de la veu, no podem esperar una coincidència absoluta entre dues mesures successives dels mateix individu. Per això, donada l'enorme variabilitat de la veu humana, tant entre individu com intraindividualment, és acceptable certa variació sempre que aquesta es mantingui dintre de certs límits. Tot i això, dues mesures repetides de la veu del mateix individu, en les mateixes condicions de registre haurien de ser el suficientment semblants per a poder confiar en elles.

En el treball que aquí es presenta s'han seleccionat, fent servir el programa Wave Surfer 1.8.5, entre les mostres recollides a la totalitat de individus participants, dos talls de veu de la vocal "a" d'una durada de dos segons cadascuna, corresponents a les parts més estables de la senyal pel que fa a la seva amplitud. Per això, s'han eliminant en tots els casos els primers 250 milisegons, en els quals l'atac de la veu dóna inestabilitat a la senyal. A més a més, els dos fragments escollits corresponen a dos moment on el so estava aïllat de qualsevol element sonor extern que pogués alterar els resultats.

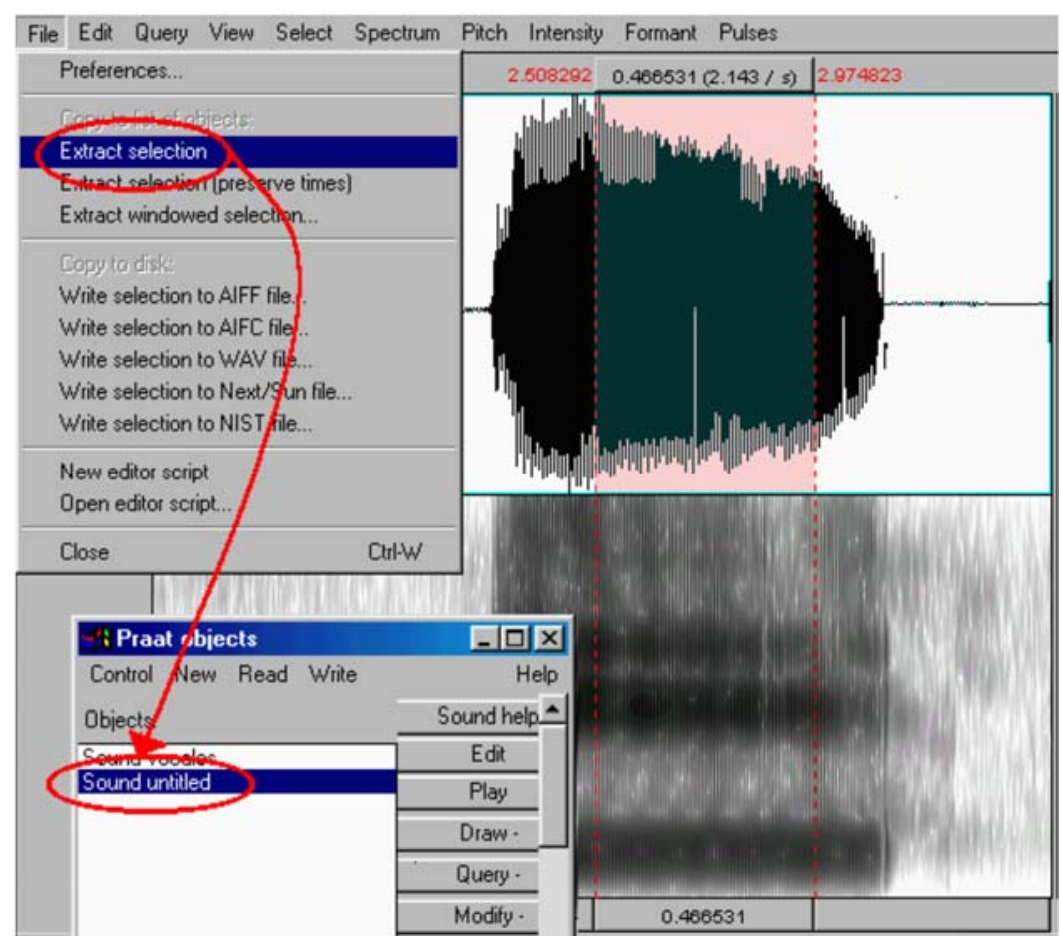

Figura 3 - De color rosa, la selecció d'una fragment de la totalitat de la vocal emesa

Un cop obtingudes les dues seleccions corresponents a la vocal "a" de cadascun dels participants en la mostra, les quals han estat seleccionades fent servir el programa Wave Surfer 1.8.5, han estat introduïdes i analitzades pel programa Praat, el qual ha permès obtenir dues taules de resultats, una per a cada tall de veu (v. un exemple dels valors obtinguts a la taula 1 ). 


\subsection{Consideracions respecte als valors normals, o standards, en l'anàlisi de la veu}

Respecte als valors normals, o standards, que habitualment es fan servir en els diferents paràmetres dels processos d'anàlisi de la veu, el primer problema que ens trobem en estudiar i comparar diferents veus, és establir que s'entén per veu normal, doncs el concepte de veu normal amb criteris objectius i absoluts no existeix. Segons Aronson (1985), hi ha alteració de la veu quan difereix de les veus d'altres persones del mateix sexe, similar edat i grup cultural, en timbre, en to, volum, i flexibilitat en la dicció.

Així doncs, tal i com està plantejat el problema respecte a una veu normal, la següent qüestió seria esbrinar de quina manera podem obtenir un grup de control- amb suposada veu normal- amb el que fer les diferents comparacions amb grups patològics (per exemple: nòduls vocals, pòlips, edema de Reinke....). Per això, al llarg dels darrers anys, diferents autors han considerat que un pacient no fumador, sense historia prèvia de trastorn vocal, sense problemes respiratoris, neurològics, nassosinusals i faringeolaringis previs, sense antecedents d'al·lèrgia, amb una audició normal i sense us professional de la veu; és el que més s'apropa al que es considera com a "veu normal".

D'aquesta manera, i per tal d'establir els valors standards en qualsevol dels programes d'anàlisi acústica de la veu, es tria un grup de control que reuneix les característiques abans descrites, i així d'aquesta manera, es creen uns llindars de normalitat en tots els paràmetres habitualment utilitzats per conèixer el grau de qualitat d'una veu. Això és el que han fet els programes habitualment utilitzats en l'anàlisi acústica, per poder oferir un valors standards, o de normalitat, aspecte que permet determinar si una veu es troba en els llindars de normalitat o bé pel contrari de la patologia.

Tenint en compte que els tres paràmetres més utilitzats habitualment per conèixer el grau de qualitat vocal són: el Jitter local, el Schimmer local i NHR, tot seguit presentem els valors de normalitat de cadascun dels esmentat paràmetres, tal i com estableix el programa Praat:

\begin{tabular}{|c|c|c|}
\hline Jitter local & Schimmer local & HNR \\
\hline $1.040 \%$ & $3.810 \%$ & $20.00 \mathrm{~dB}$ \\
\hline
\end{tabular}

Taula 2 - Valors de normalitat dels paràmetres de qualitat vocal

\section{RESULTATS}

Un cop recollides les dades a la fase experimental i, posteriorment, introduïdes i processades mitjançant el programa Praat, per a l'anàlisi objectiva de la qualitat vocal; tot seguit presentem els resultats que han estat obtinguts, els quals ens permetran conèixer l'estat de la qualitat vocal dels mestres participants en la recerca practicada.

\subsection{Resultats globals}

En primer lloc es presenten els resultats globals de la totalitat dels participants, en una taula en la qual hi figuren classificats per grups. En aquesta taula general, en primer lloc hi figuren els mestres d'educació infantil, els quals estan dividits en dos grups: mestres novells i mestres amb experiència, seguit pels mestres d'educació primària, també 
classificats en els mateixos dos grups. Li segueixen els mestres d'educació física, els mestres de llengües estrangeres, i per últim, els mestres de música.

\begin{tabular}{|l|l|l|l|l|l|}
\hline Especialitat & $\begin{array}{l}\text { Mitjana } \\
\text { d'edat }\end{array}$ & $\begin{array}{l}\text { Ex. } \\
\text { Prof. }\end{array}$ & Jitter \% & Schimmer \% & HNR (dB) \\
\hline Ed.Infantil novells & 27 & 4.7 & 0.500 & 12.550 & 13.911 \\
\hline Ed.Infantil amb experiència & 46.2 & 20.7 & 0.716 & 11.186 & 13.447 \\
\hline Ed. Primària novells & 26.1 & 3.5 & 0.601 & 10.550 & 13.921 \\
\hline Ed.Primària amb expreriència & 52.9 & 30.7 & 0.335 & 8.227 & 15.310 \\
\hline Ed. Física & 35.5 & 11.5 & 0.403 & 7.063 & 15.650 \\
\hline Llengües Estrangeres & 39.5 & 14.3 & 0.713 & 10.974 & 14.784 \\
\hline Música & 34.5 & 10.7 & 0.279 & 8.989 & 17.878 \\
\hline Valors mitjans de la recerca & $\mathbf{3 7 . 3}$ & $\mathbf{1 3 . 7}$ & $\mathbf{0 . 5 0 6}$ & $\mathbf{9 . 9 3 4}$ & $\mathbf{1 4 . 9 8 5}$ \\
\hline
\end{tabular}

Taula 3 - Resultats globals

A cada taula de resultats $i$, al costat de cada grup de docents, es poden observar els tres valors recollits. En primer lloc el Jitter, desprès el Schimmer, i per últim, el HNR. A la darrera fila de cada grup es presenten els valors mitjans obtinguts dins de cada especialitat per a cadascun dels tres paràmetres analitzats.

\subsection{Resultats per especialitats}

Tot seguit, i en tan bon punt han estat coneguts els resultats globals per especialitat, tot seguit es mostraran els resultats per especialitats en els quals s'especifiquen la totalitat de dades recollides per a cada subjecte participant en l'estudi. En primer lloc, es presenten els resultats dels anomenats mestres generalistes: els d'educació infantil i els mestres d'educació primària. En aquest sentit val a dir que, atès que en alguns centres educatius els mestres més joves porten 10 anys treballant, és a dir que no són mestres novells, i en d'altres centres porten poc temps no s'ha pogut contrastar les diferències entre els mestres novells d'infantil i de primària i dels mestres més veterans per centres.

Per això aquests valors han estat contemplats igualment, però sense atribució a un centre educatiu concret. Es a dir, s'han pres els deu mestres més novells de tota la mostra, tant d'educació infantil, com d'educació primària, $i$ han estat contrastats amb els deu més veterans de ambdues especialitats.

Així doncs, seguidament es presenten les taules corresponents als mestres en el següent ordre: mestres d'educació infantil novells, mestres d'educació infantil amb experiència, mestres d'educació primària novells, mestres d'educació primària amb experiència. 


\begin{tabular}{|c|c|c|c|c|c|}
\hline Informants & Edat & $\begin{array}{c}\text { Ex. } \\
\text { Prof. }\end{array}$ & Jitter \% & Schimmer \% & HNR (dB) \\
\hline B0213 & 27 & 3 & 0.198 & 10.143 & 17.513 \\
\hline C0224 & 28 & 7 & 0.463 & 12.432 & 15.947 \\
\hline D0189 & 27 & 4 & 0.382 & 10.009 & 13.211 \\
\hline D0190 & 29 & 4 & 0.976 & 18.533 & 11.329 \\
\hline E0200 & 27 & 6 & 0.202 & 7.325 & 18.992 \\
\hline E0198 & 25 & 5 & 0.453 & 20.730 & 12.300 \\
\hline F0209 & 28 & 6 & 0.488 & 9.986 & 10.699 \\
\hline G0162 & 25 & 5 & 0.533 & 14.380 & 11.326 \\
\hline H0184 & 27 & 3 & 0.390 & 5.587 & 18.363 \\
\hline J0177 & 27 & 4 & 0.923 & 16.377 & 9.432 \\
\hline Valors mitjans & $\mathbf{2 7}$ & $\mathbf{4 . 7}$ & $\mathbf{0 . 5 0 0}$ & $\mathbf{1 2 . 5 5 0}$ & $\mathbf{1 3 . 9 1 1}$ \\
\hline
\end{tabular}

Taula 4 - Mestres d'educació infantil novells

\begin{tabular}{|c|c|c|c|c|c|}
\hline Informants & Edat & $\begin{array}{c}\text { Ex. } \\
\text { Prof. }\end{array}$ & Jitter \% & Schimmer \% & HNR (dB) \\
\hline A0227 & 41 & 18 & 0.301 & 7.047 & 13.502 \\
\hline C0223 & 54 & 27 & 1.664 & 15.060 & 7.600 \\
\hline D0196 & 41 & 19 & 0.656 & 12.137 & 12.848 \\
\hline E0199 & 43 & 9 & 1.101 & 16.969 & 8.693 \\
\hline E0237 & 42 & 20 & 0.235 & 6.090 & 20.995 \\
\hline G0254 & 48 & 25 & 0.218 & 5.286 & 17.025 \\
\hline G0256 & 46 & 24 & 0.441 & 14.428 & 11.195 \\
\hline H0186 & 48 & 25 & 0.444 & 10.577 & 12.877 \\
\hline I0244 & 44 & 20 & 0.283 & 5.487 & 18.062 \\
\hline J0175 & 55 & 20 & 1.825 & 18.784 & 11.682 \\
\hline Valors mitjans & $\mathbf{4 6 , 2}$ & $\mathbf{2 0 , 7}$ & $\mathbf{0 . 7 1 6}$ & $\mathbf{1 1 . 1 8 6}$ & $\mathbf{1 3 . 4 4 7}$ \\
\hline
\end{tabular}

Taula 5 - Mestres d'educació infantil amb experiència 


\begin{tabular}{|c|c|c|c|c|c|}
\hline Informants & Edat & $\begin{array}{c}\text { Ex. } \\
\text { Prof. }\end{array}$ & Jitter \% & Schimmer \% & HNR (dB) \\
\hline B0214 & 23 & 3 & 0.644 & 12.858 & 9.559 \\
\hline C0225 & 26 & 2 & 0.290 & 6.886 & 18.922 \\
\hline D0191 & 22 & 1 & 0.628 & 9.850 & 13.036 \\
\hline E0234 & 30 & 5 & 0.333 & 2.311 & 17.925 \\
\hline F0211 & 27 & 2 & 0.590 & 16.375 & 9.166 \\
\hline G0169 & 25 & 3 & 0.442 & 4.543 & 18.549 \\
\hline H0185 & 24 & 2 & 0.260 & 13.763 & 12.032 \\
\hline I0246 & 23 & 3 & 0.540 & 8.218 & 17.795 \\
\hline I0249 & 29 & 8 & 0.318 & 7.011 & 17.140 \\
\hline J0180 & 32 & 6 & 1.973 & 23.686 & 5.086 \\
\hline Valors mitjans & $\mathbf{2 6 , 1}$ & $\mathbf{3 . 5}$ & $\mathbf{0 . 6 0 1}$ & $\mathbf{1 0 . 5 5 0}$ & $\mathbf{1 3 . 9 2 1}$ \\
\hline
\end{tabular}

Taula 6 - Mestres d'educació primària novells

\begin{tabular}{|c|c|c|c|c|c|}
\hline Informants & Edat & $\begin{array}{c}\text { Ex. } \\
\text { Prof. }\end{array}$ & Jitter \% & Schimmer \% & HNR (dB) \\
\hline A0229 & 51 & 30 & 0.435 & 10.719 & 12.972 \\
\hline B0217 & 65 & 39 & 0.261 & 6.856 & 18.899 \\
\hline C0219 & 51 & 27 & 0.217 & 4.422 & 18.895 \\
\hline D0192 & 60 & 40 & 0.504 & 6.223 & 16.793 \\
\hline F0206 & 47 & 24 & 0.236 & 7.987 & 15.413 \\
\hline G0258 & 47 & 25 & 0.272 & 6.623 & 15.349 \\
\hline H0182 & 59 & 38 & 0.364 & 9.610 & 16.020 \\
\hline I0240 & 48 & 28 & 0.205 & 4.524 & 19.483 \\
\hline I0242 & 51 & 29 & 0.340 & 9.555 & 13.810 \\
\hline J0178 & 50 & 27 & 0.520 & 15.758 & 5.474 \\
\hline Valors mitjans & $\mathbf{5 2 . 9}$ & $\mathbf{3 0 . 7}$ & $\mathbf{0 . 3 3 5}$ & $\mathbf{8 . 2 2 7}$ & $\mathbf{1 5 . 3 1 0}$ \\
\hline
\end{tabular}

Taula 7- Mestres d'educació primària amb experiència 


\begin{tabular}{|c|c|c|c|c|c|}
\hline Informants & Edat & $\begin{array}{c}\text { Ex. } \\
\text { Prof. }\end{array}$ & Jitter \% & Schimmer \% & HNR (dB) \\
\hline A0230 & 50 & 26 & 0.401 & 5.782 & 14.233 \\
\hline B0215 & 25 & 4 & 0.273 & 6.979 & 11.830 \\
\hline C0220 & 28 & 6 & 0.319 & 3.505 & 21.404 \\
\hline D0193 & 33 & 11 & 0.401 & 6.408 & 15.811 \\
\hline E0236 & 31 & 4 & 0.348 & 3.780 & 18.264 \\
\hline F0208 & 31 & 7 & 0.322 & 5.565 & 18.785 \\
\hline G0163 & 33 & 4 & 0.332 & 6.538 & 15.460 \\
\hline H0187 & 44 & 18 & 0.346 & 7.905 & 14.603 \\
\hline I0243 & 49 & 27 & 0.597 & 13.678 & 12.693 \\
\hline J0179 & 31 & 8 & 0.697 & 10.492 & 13.431 \\
\hline Valors mitjans & $\mathbf{3 5 . 5}$ & $\mathbf{1 1 . 5}$ & $\mathbf{0 . 4 0 3}$ & $\mathbf{7 . 0 6 3}$ & $\mathbf{1 5 . 6 5 0}$ \\
\hline
\end{tabular}

Taula 8 - Mestres d'educació física

\begin{tabular}{|c|c|c|c|c|c|}
\hline Informants & Edat & $\begin{array}{c}\text { Ex. } \\
\text { Prof. }\end{array}$ & Jitter \% & Schimmer \% & HNR (dB) \\
\hline A0233 & 45 & 20 & 0.612 & 10.873 & 19.112 \\
\hline B0216 & 33 & 6 & 0.398 & 11.410 & 13.398 \\
\hline C0221 & 49 & 24 & 0.655 & 8.843 & 16.449 \\
\hline D0188 & 34 & 3 & 0.440 & 11.379 & 15.879 \\
\hline E0238 & 33 & 10 & 0.498 & 7.972 & 10.497 \\
\hline F0205 & 33 & 10 & 0.595 & 12.638 & 13.498 \\
\hline G0168 & 27 & 4 & 0.364 & 5.091 & 18.760 \\
\hline H0183 & 38 & 16 & 0.812 & 13.652 & 13.182 \\
\hline I0245 & 52 & 30 & 2.383 & 14.601 & 11.866 \\
\hline J0176 & 51 & 20 & 0.376 & 13.282 & 15.207 \\
\hline Valors mitjans & $\mathbf{3 9 . 5}$ & $\mathbf{1 4 . 3}$ & $\mathbf{0 . 7 1 3}$ & $\mathbf{1 0 . 9 7 4}$ & $\mathbf{1 4 . 7 8 4}$ \\
\hline
\end{tabular}

Taula 9 - Mestres de llengües estrangeres 


\begin{tabular}{|c|c|c|c|c|c|}
\hline Informants & Edat & $\begin{array}{c}\text { Ex. } \\
\text { Prof. }\end{array}$ & Jitter \% & Schimmer \% & HNR (dB) \\
\hline A0231 & 36 & 16 & 0.461 & 9.303 & 19.003 \\
\hline B0218 & 33 & 9 & 0.271 & 6.542 & 19.063 \\
\hline C0222 & 57 & 30 & 0.138 & 8.035 & 18.899 \\
\hline D0195 & 32 & 7 & 0.264 & 6.234 & 19.959 \\
\hline E0201 & 26 & 5 & 0.342 & 8.656 & 17.588 \\
\hline F0210 & 24 & 1 & 0.357 & 10.146 & 16.326 \\
\hline G0255 & 34 & 7 & 0.635 & 12.974 & 14.378 \\
\hline H0181 & 31 & 8 & 0.229 & 7.018 & 18.165 \\
\hline I0241 & 26 & 4 & 0.458 & 15.184 & 14.752 \\
\hline J0260 & 46 & 20 & 0.275 & 5.802 & 20.653 \\
\hline Valors mitjans & $\mathbf{3 4 . 5}$ & $\mathbf{1 0 . 7}$ & $\mathbf{0 . 2 7 9}$ & $\mathbf{8 . 9 8 9}$ & $\mathbf{1 7 . 8 7 8}$ \\
\hline
\end{tabular}

Taula 10 - Mestres d'educació musical

\section{DISCUSSIÓ DE LES DADES}

En aquest apartat analitzarem les dades obtingudes a la part experimental i procedirem a la seva discussió. Val a dir que les anàlisis acústiques practicades han permès mesurar i, posteriorment, conèixer, d'una manera totalment objectiva, la situació de tres paràmetres de la qualitat vocal de cadascun dels diferents mestres participants en les medicions practicades, valors que ens ajuden a comprendre el grau de qualitat vocal, o bé de disfonia, en què es troben la totalitat de les veus analitzades.

Per tot això, de les dades obtingudes en la medició de la qualitat vocal dels diferents participants en la mostra d'aquesta recerca, tot seguit es presenten una sèrie d'aspectes que es poden interpretar com a conseqüència de les esmentades dades recollides. En primer lloc, comentarem els resultats obtinguts considerant la totalitat dels mestres participants, és a dir globalment i, en segon lloc, repassarem els valors per grups segons l'especialitat a què pertanyen, tot seguin l'ordre en què han estat presentats els resultats: mestres d'educació infantil, mestres d'educació primària, mestres d'educació física, mestres de llengües estrangeres i mestres d'educació musical.

\subsection{Dades globals}

Pel que fa als resultats globals de l'estudi, el primer paràmetre estudiat -el Jitter- dóna un resultat que es pot situar clarament dins de la normalitat, doncs el valor mitjà resultant ha estat de $0.506 \%$, sent el valor standard de $1.040 \%$. Tot i això, val a dir que, tal i com anuncien Piñeiro i Pire (2002), aquest valor no té relació directa amb el grau de disfonia, el que significa que una persona amb disfonia pot tranquil-lament donar un resultat que està dins els paràmetres considerats com de normalitat. 


\begin{tabular}{|l|l|}
\hline Jitter normal & Jitter alterat \\
De 0 a $1,040 \%$ & Més de de $1,050 \%$ \\
\hline $92,85 \%$ & $7,14 \%$ \\
\hline 65 persones & 5 persones \\
\hline
\end{tabular}

Taula 11 - Valors globals de Jitter

Així doncs, es tracta d'un aspecte que no ens permet determinar amb precisió el grau de qualitat vocal dels mestres analitzats. Tot i això, val a dir que un 7,14\% -5 persones- han donat un valor molt elevat, el qual els situa en una zona d'anormalitat del paràmetre, mentre que el $92,85 \%$ està clarament dins la zona considerada com de normalitat del paràmetre.

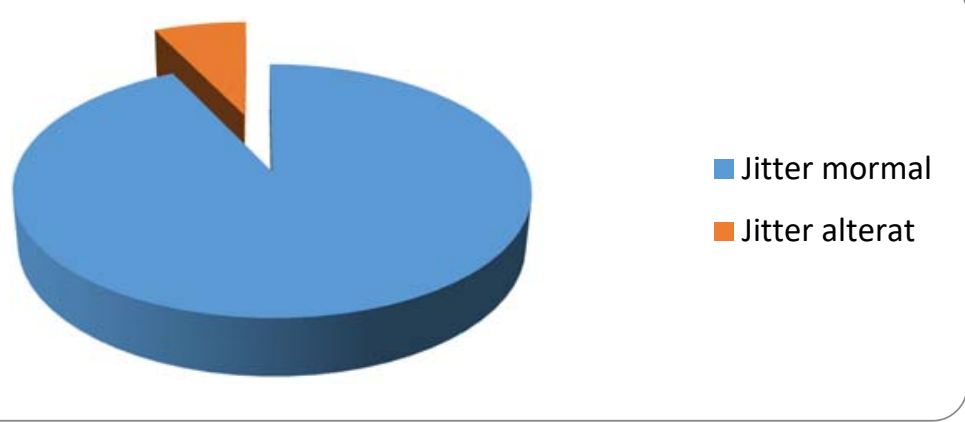

Gràfic 1 - Valors globals de Jitter

En canvi, el segon valor analitzat, el Schimmer, tal i com sosté Wolfe et al. (1995) si que guarda una relació directa amb el grau de disfonia que presenta la veu d'una persona, doncs si aquest està alterat vol dir que existeix algun grau de disfonia en la veu. Pel que fa als resultats del Schimmer en la mostra d'aquest estudi, el valor mitjà global obtingut ha estat de $9.934 \%$ valor que supera el doble de lo recomanable com a valor idoni, el qual està situat en $3.810 \%$. De tota manera, cal veure la totalitat dels components de la mostra en la següent taula, en la que es mostren els resultats en quatre categories diferents:

\begin{tabular}{|l|l|l|}
\hline Schimmer normal & Schimmer normal + 50\% & Schimmer Alterat \\
\hline De 0 a $3,8 \%$ & De $3,9 \%$ a $5,7 \%$ & A partir de $5,8 \%$ \\
\hline $4.28 \%$ & $11.42 \%$ & $84.28 \%$ \\
\hline 3 persones & 8 persones & 59 persones \\
\hline
\end{tabular}

Taula 12 - Valors globals de Shimmer

Dels resultats obtinguts, només el $4,28 \%$ de la mostra -3 persones- han presentat el valor standard de normalitat. El 11,42\% -8 persones- han presentat un valor de fins al 50\% més del valor normal, la qual cosa, tot $\mathrm{i}$ que el seu valor està alterat lleument, podem interpretar-la com de proximitat als paràmetres habituals, $i$ per tant considerarem aquest grup també dins la normalitat.

Un 84,28\% -59 persones- presenten valors amb el schimmer alterat, doncs són veus que es situen fora de la franja de fins a un 50\% més dels valors normatius, sent resultats que s'allunyen molt dels que són els paràmetres standaritzats 


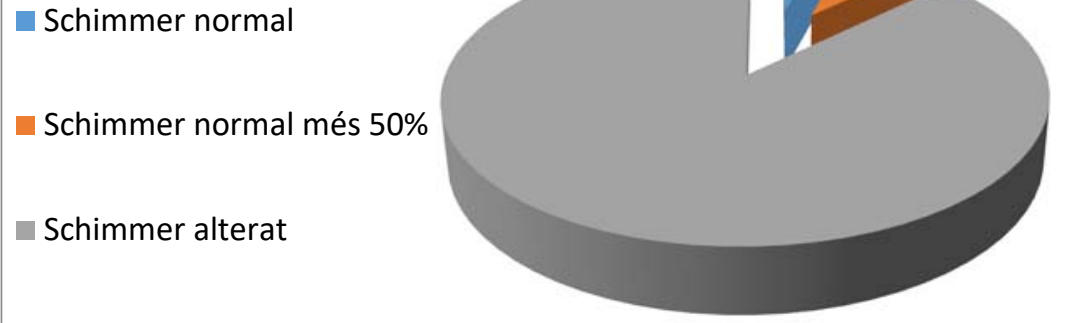

Gràfic 2 - Valors globals de shimmer 1

En definitiva, podem concloure que, pel que fa a aquest paràmetre, hi ha un $15.70 \%$ de veus que es poden considerar, en conjunt, com d'una "certa" qualitat vocal i, per tant, dins de la normalitat. D'altra banda, un $84.28 \%$ de la mostra correspon als informants que a nivell global han presentat uns valors de schimmer alterat, que molt allunyat del valor standard, es tracten de valors que estan relacionats clarament amb la disfonia.

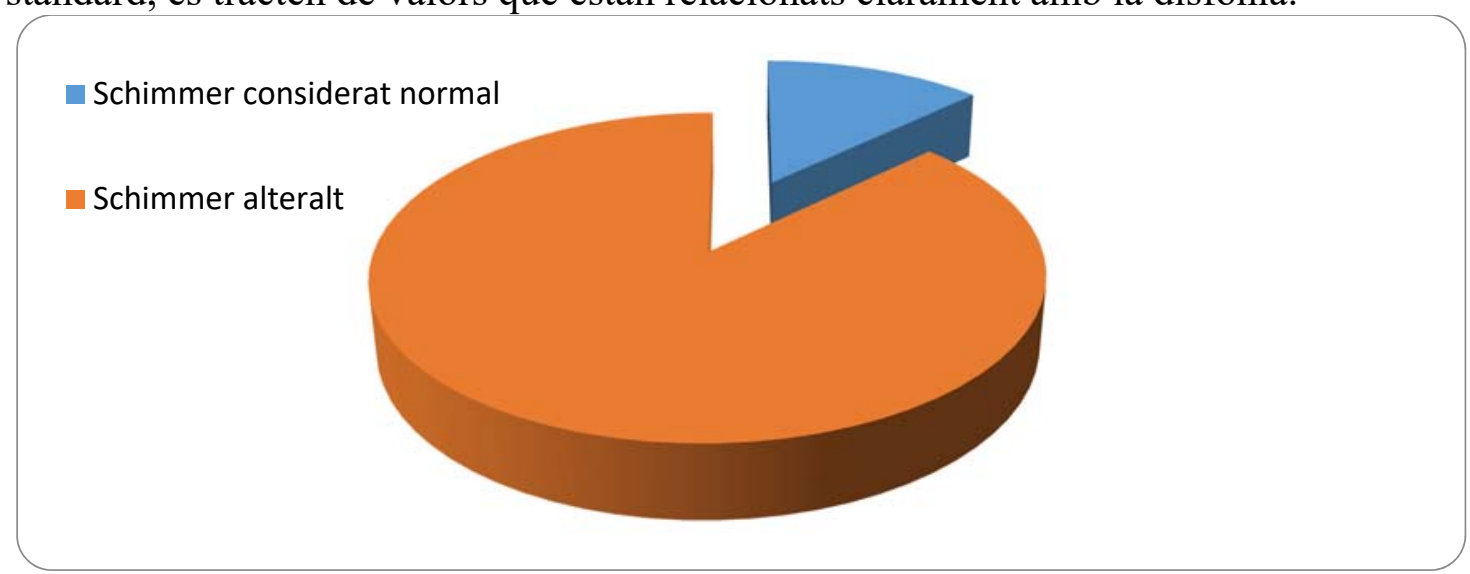

\section{Gràfic 3 - Valors globals de shimmer 2}

El tercer paràmetre valorat per conèixer la qualitat vocal dels mestres analitzats ha estat el HNR, que correspon a la mesura de la quantitat de soroll que hi ha en la veu. Aquest valor, i al igual que el paràmetre anterior, també dóna un resultat valor força alterat, atès que si el valor normal es situa al voltant dels $20.00 \mathrm{~dB}$, la mitjana dels mestres analitzats en aquest estudi està en $14.985 \mathrm{~dB}$. Val a dir que, quan més es superi els $20.00 \mathrm{~dB}$ de més qualitat és la veu.

\begin{tabular}{|l|l|}
\hline $\begin{array}{l}\text { HNR normal } \\
\text { proper a l'entorn de } 20 \mathrm{~dB} \text { o més }\end{array}$ & $\begin{array}{l}\text { HNR alterat } \\
\text { de } 0 \mathrm{~dB} \text { fins l'entorn de } 20 \mathrm{~dB}\end{array}$ \\
\hline $11.42 \%$ & $88.57 \%$ \\
\hline 8 persones & 62 persones \\
\hline
\end{tabular}

Taula 13 - Valors globals de HNR

Dels resultats obtinguts, només el $11.42 \%$ de la mostra -8 persones- han presentat els valors de normalitat, mentre que el $88.57 \%-62$ persones- han presentat uns valors de HNR alterat. 


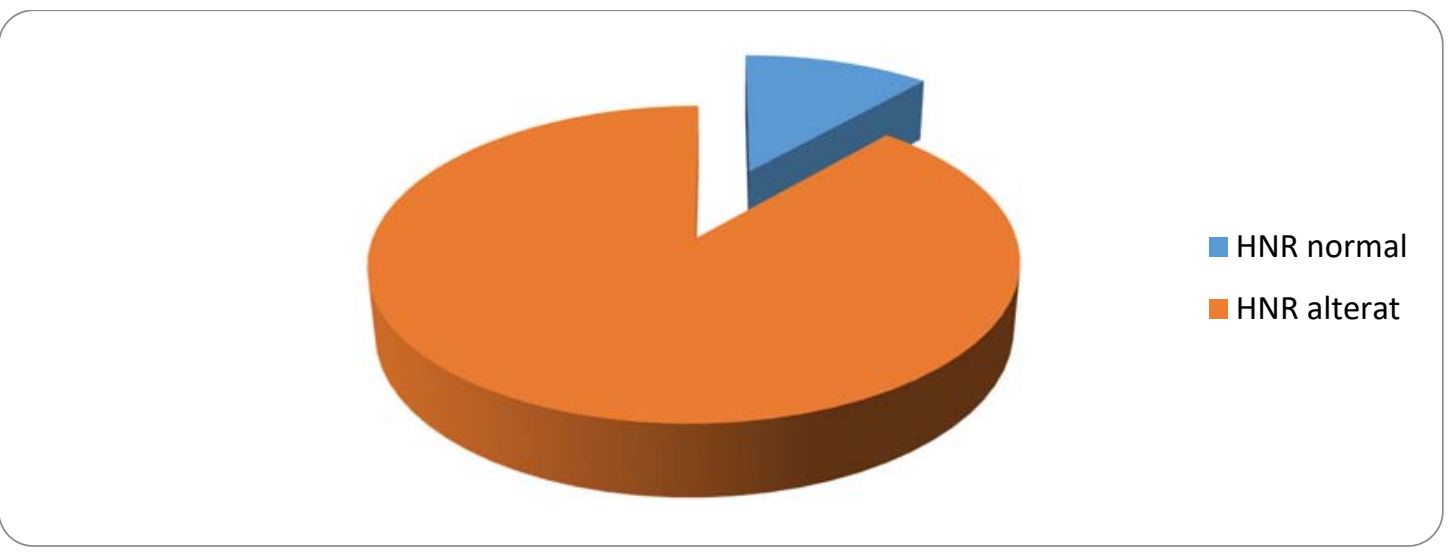

Gràfic 4 - Valors globals de HNR

\subsection{Dades per especialitats}

Després d'haver comentat els resultats obtinguts considerant la totalitat dels mestres participants, és a dir globalment, tot seguit repassarem els valors per grups segons l'especialitat a què pertanyen: mestres d'educació infantil, mestres d'educació primària, mestres d'educació física, mestres de llengües estrangeres i mestres d'educació musical 6.2.1. Mestres d'Educació Infantil

En el cas dels mestres d'educació infantil, en primer lloc presentem els resultats dels que hem anomenat com a mestres novells. Pel que fa al primer paràmetre de la veu analitzat, Jitter, el valor mitjà resultant d'aquets informants ha estat de $0.500 \%$, valor que es situa dins el valors standards de normalitat establerts (1.040\%), per tant, en aquest cas el $100 \%$ de la mostra ha obtingut resultats dins de la normalitat.

D'altra banda, els resultats del segon paràmetre analitzat, Schimmer, presenta un valor mitjà global de $12,550 \%$ valor que es situa fora dels valors standards de normalitat establerts $(3.810 \%)$ o el $50 \%$ més, per tant, en aquest cas el $90 \%$ de la mostra ha obtingut resultats alterats.

\begin{tabular}{|l|l|l|}
\hline Schimmer normal & Schimmer normal + 50\% & Schimmer Alterat \\
\hline De 0 a $3,8 \%$ & De $3,9 \%$ a $5,7 \%$ & A partir de $5,8 \%$ \\
\hline $0 \%$ & $10 \%$ & $90 \%$ \\
\hline 0 persones & 1 persones & 9 persones \\
\hline
\end{tabular}

Taula 14 - Valors de Schimmer dels mestres d'educació infantil novells

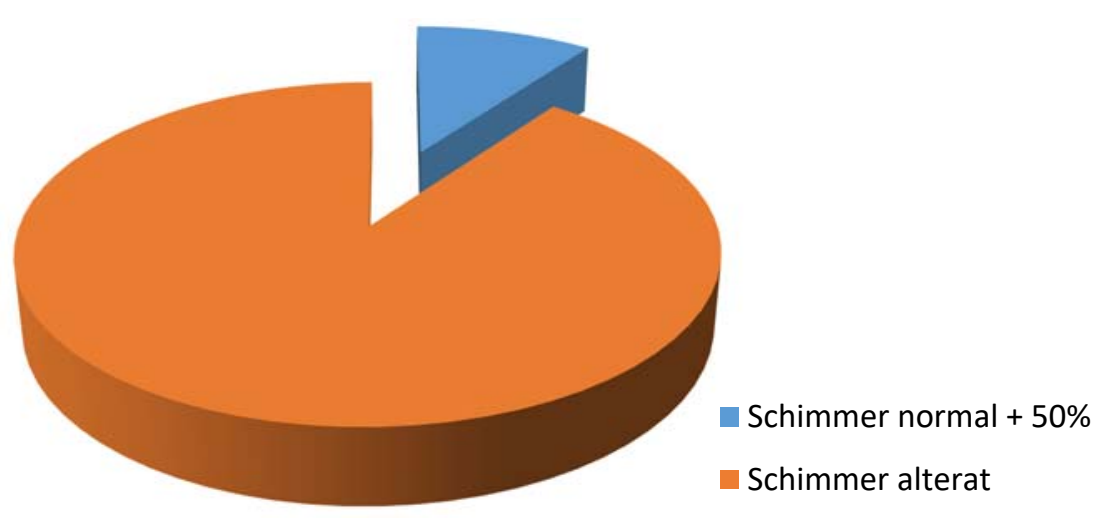




\section{Gràfic 5 - Valors de Schimmer dels mestres d'educació infantil novells}

El tercer paràmetre valorat per conèixer la qualitat vocal dels mestres analitzats ha estat el HNR. Aquest valor ha donat un resultat força alterat (13.911dB), atès que el valor normal es situa al voltant dels $20.00 \mathrm{~dB}$. per tant, en aquest cas el $100 \%$ de la mostra ha obtingut resultats alterats.

\begin{tabular}{|l|l|}
\hline $\begin{array}{l}\text { HNR normal } \\
\text { proper a l'entorn de } 20 \mathrm{~dB} \text { o més }\end{array}$ & $\begin{array}{l}\text { HNR alterat } \\
\text { de } 0 \mathrm{~dB} \text { fins l'entorn de } 20 \mathrm{~dB}\end{array}$ \\
\hline $0 \%$ & $100 \%$ \\
\hline 0 persones & 10 persones \\
\hline
\end{tabular}

Taula 15 - Valors de HNR dels mestres d'educació infantil novells

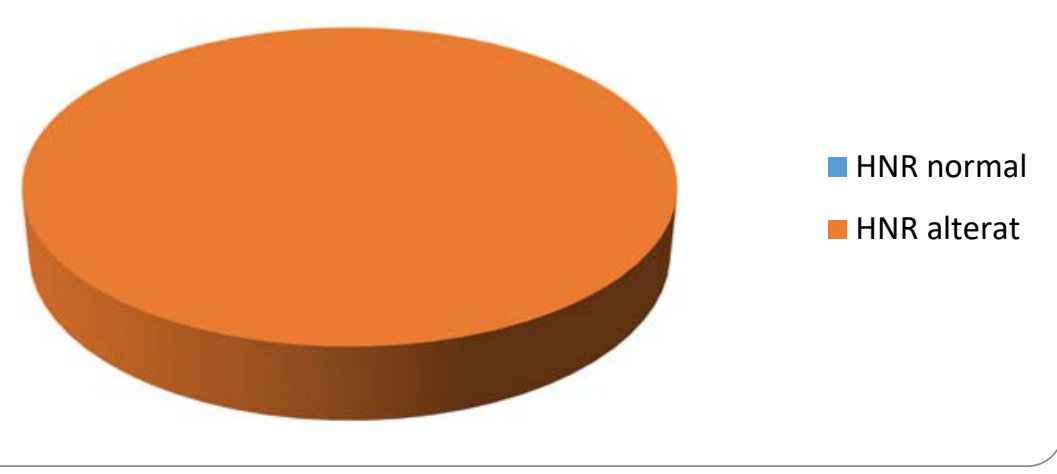

Gràfic 5 - Valors de HNR dels mestres d'educació infantil novells

En el cas dels mestres d'educació infantil, en segon terme presentarem els resultats dels que hem anomenat com a mestres amb experiència. Pel que fa al primer paràmetre de la veu analitzat, Jitter, el valor mitjà resultant d'aquets informants ha estat de $0.716 \%$, valor que es situa dins el valors standards de normalitat establerts. Tot i que cal destacar que tres subjectes integrants d'aquesta mostra $-30 \%$ - han obtingut resultats alterats respecte del valor standard (1.040\%) mentre que la resta del grup, que representa un $70 \%$ ha obtingut uns resultats dins de la normalitat.

D'altra banda, els resultats del segon paràmetre analitzat, Schimmer, presenta un valor mitjà global de $11.186 \%$, valor que es situa fora dels valors standards de normalitat establerts (3.810\%). Tot i això, cal destacar que 2 subjectes integrants d'aquesta mostra $20 \%$ - han obtingut resultats dins la normalitat respecte del valor standard (3.810\%) o el $50 \%$ més, mentre que la resta del grup, que representa un $80 \%$ ha obtingut uns resultats alterats.

\begin{tabular}{|l|l|l|}
\hline Schimmer normal & Schimmer normal + 50\% & Schimmer Alterat \\
\hline De 0 a $3,8 \%$ & De $3,9 \%$ a $5,7 \%$ & A partir de5,8\% \\
\hline $0 \%$ & $20 \%$ & $80 \%$ \\
\hline 0 persones & 2 persones & 8 persones \\
\hline
\end{tabular}

Taula 16 - Valors de Schimmer dels mestres d'educació infantil amb experiència 


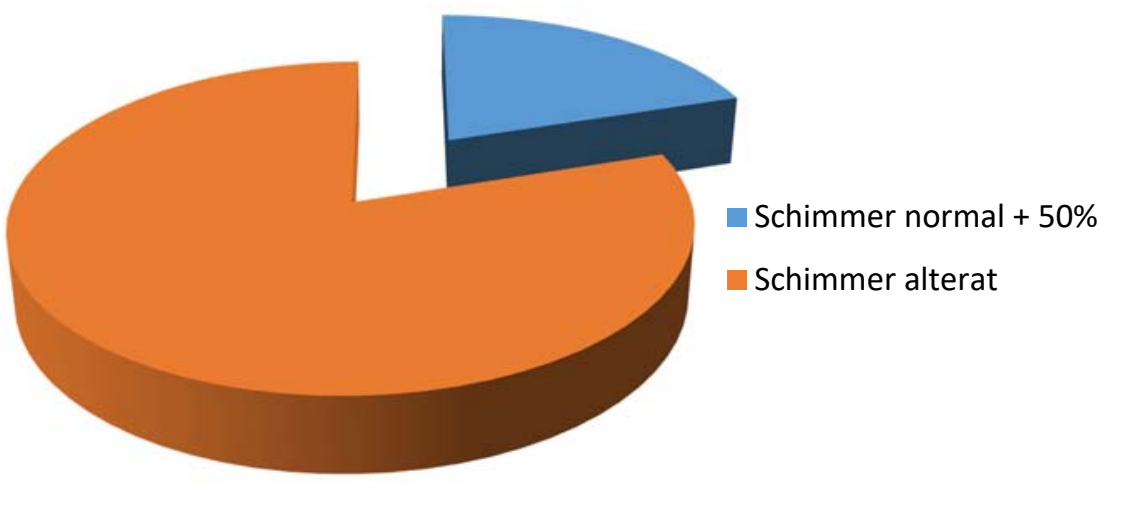

Gràfic 6 - Valors de Schimmer dels mestres d'educació infantil amb experiència

El tercer paràmetre valorat per conèixer la qualitat vocal dels mestres analitzats ha estat el HNR. Aquest valor ha donat un resultat força alterat, $13.447 \mathrm{~dB}$, atès que el valor normal es situa al voltant dels $20.00 \mathrm{~dB}$. Cal destacar que 1 subjecte integrant d'aquesta mostra $-10 \%$ - ha obtingut un resultat considerats dins la normalitat respecte del valor standard, mentre que la resta del grup, que representa un $90 \%$, ha obtingut uns resultats alterats.

\begin{tabular}{|l|l|}
\hline $\begin{array}{l}\text { HNR normal } \\
\text { proper a l'entorn de } 20 \mathrm{~dB} \text { o més }\end{array}$ & $\begin{array}{l}\text { HNR alterat } \\
\text { de } 0 \mathrm{~dB} \text { fins l'entorn de } 20 \mathrm{~dB}\end{array}$ \\
\hline $10 \%$ & $90 \%$ \\
\hline 1 persona & 90 persones \\
\hline
\end{tabular}

Taula 17 - Valors de HNR dels mestres d'educació infantil amb experiència

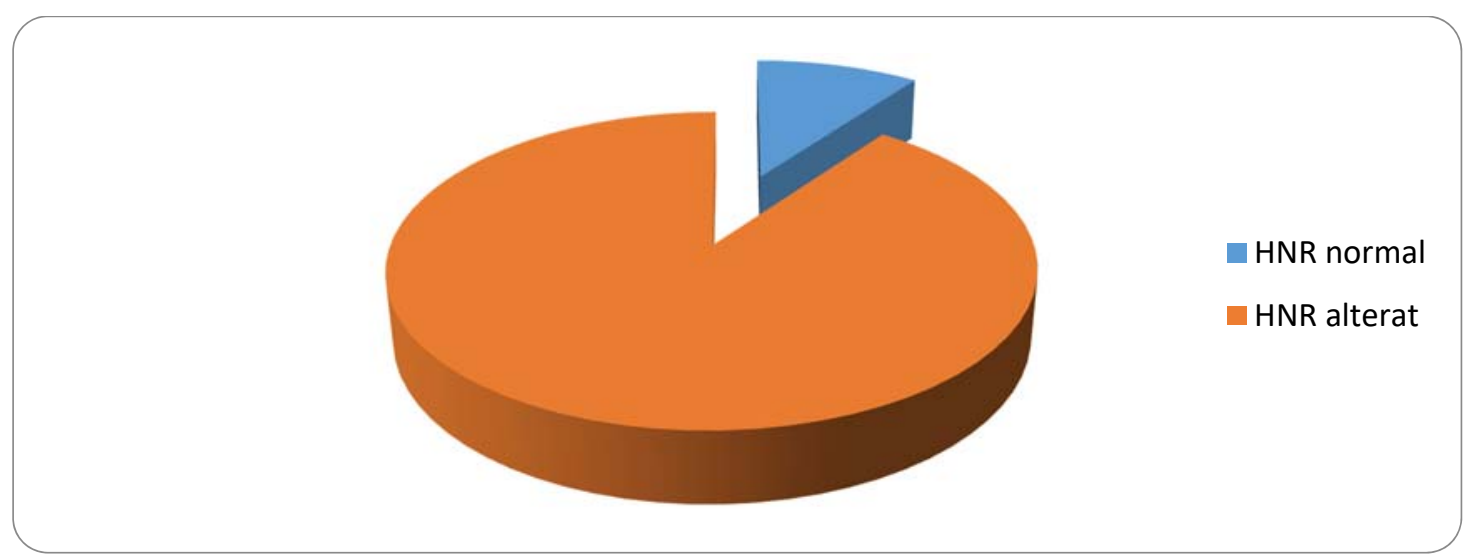

Gràfic 7 - Valors de HNR dels mestres d'educació infantil amb experiència

\subsubsection{Mestres d'Educació Primària}

En el cas dels mestres d'educació primària, en primer lloc presentem els resultats del que hem anomenat com a mestres novells. Pel que fa al primer paràmetre de la veu analitzat, Jitter, el valor mitjà resultant d'aquets informants ha estat de $0.601 \%$, valor que es situa dins el valors standards de normalitat establerts. Tot i que un subjecte integrant d'aquesta mostra $-10 \%$ - ha obtingut resultats alterats respecte del valor standard 
(1.040\%), la resta del grup, que representa un $90 \%$, ha obtingut uns resultats dins de la normalitat.

D'altra banda, els resultats del segon paràmetre analitzat, Schimmer, presenta un valor mitjà global de $10.550 \%$ valor que es situa fora dels valors standards de normalitat establerts (3.810\%). Tot i això, cal destacar que 2 subjectes integrants d'aquesta mostra $20 \%$ - han obtingut resultats dins la normalitat respecte del valor standard (3.810\%) o el $50 \%$ més, mentre que la resta del grup, que representa un $80 \%$ ha obtingut uns resultats alterats.

\begin{tabular}{|l|l|l|}
\hline Schimmer normal & Schimmer normal + 50\% & Schimmer Alterat \\
\hline De 0 a $3,8 \%$ & De $3,9 \%$ a $5,7 \%$ & A partir de $5,8 \%$ \\
\hline $10 \%$ & $10 \%$ & $80 \%$ \\
\hline 1 persona & 1 persona & 8 persones \\
\hline
\end{tabular}

Taula 18 - Valors de Schimmer dels mestres d'educació primària novells

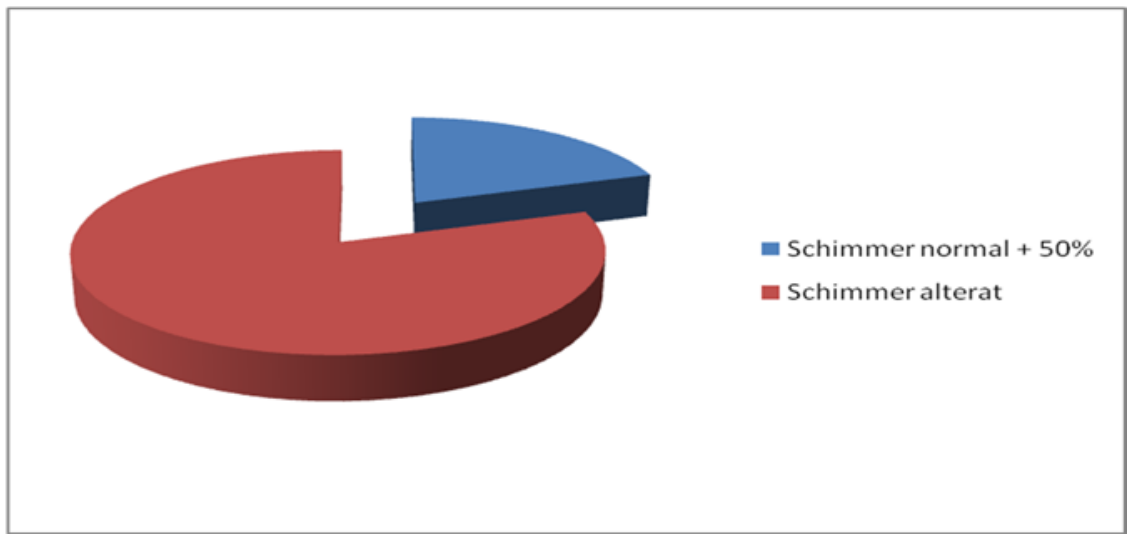

Gràfic 8 - Valors de Schimmer dels mestres d'educació primària novells

El tercer paràmetre valorat per conèixer la qualitat vocal dels mestres analitzats ha estat el HNR. Aquest valor ha donat un resultat força alterat, $13.921 \mathrm{~dB}$, atès que el valor normal es situa al voltant dels $20.00 \mathrm{~dB}$. per tant, en aquest cas el $100 \%$ de la mostra ha obtingut resultats alterats.

\begin{tabular}{|l|l|}
\hline $\begin{array}{l}\text { HNR normal } \\
\text { proper a l'entorn de } 20 \mathrm{~dB} \text { o més }\end{array}$ & $\begin{array}{l}\text { HNR alterat } \\
\text { de } 0 \mathrm{~dB} \text { fins l'entorn de } 20 \mathrm{~dB}\end{array}$ \\
\hline $0 \%$ & $100 \%$ \\
\hline 0 persones & 10 persones \\
\hline
\end{tabular}

Taula 19 - Valors de HNR dels mestres d'educació primària novells 


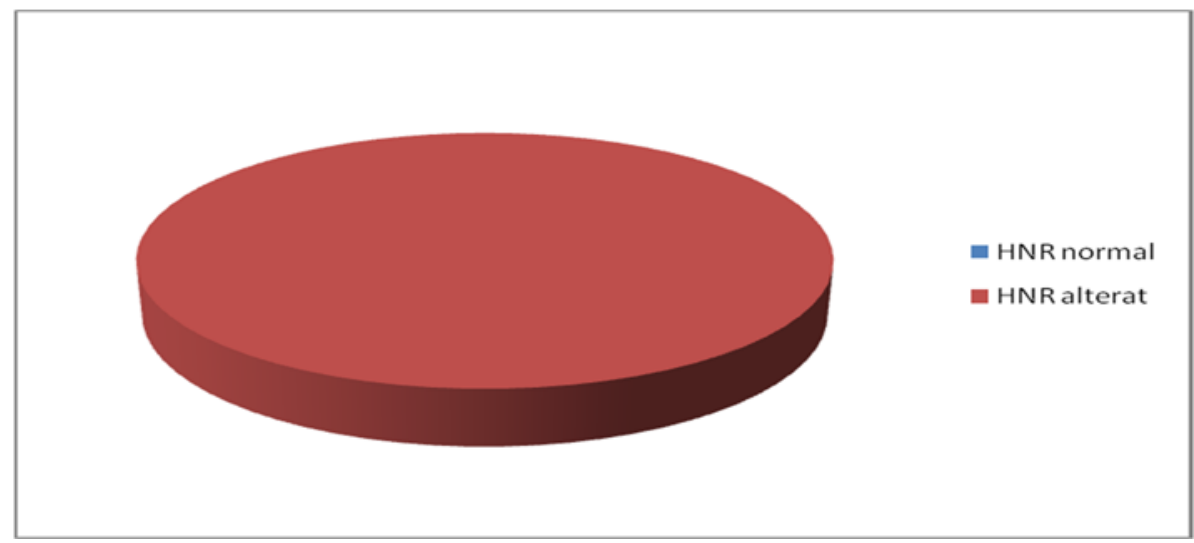

Gràfic 9 - Valors de HNR dels mestres d'educació primària novells

En el cas dels mestres d'educació primària, en segon terme presentarem els resultats del que hem anomenat com a mestres amb experiència. Pel que fa al primer paràmetre de la veu analitzat, Jitter, el valor mitjà resultant d'aquets informants ha estat de $0.335 \%$, valor que es situa dins el valors standards de normalitat establerts, per tant, en aquest cas el $100 \%$ de la mostra ha obtingut resultats dins de la normalitat.

D'altra banda, els resultats del segon paràmetre analitzat, Schimmer, presenta un valor mitjà global de $8.227 \%$ valor que es situa fora dels valors standards de normalitat establerts (3.810\%). Tot i això, cal destacar que 2 subjectes integrants d'aquesta mostra $20 \%$ - han obtingut resultats dins la normalitat respecte del valor standard $(3.810 \%)$ o el $50 \%$ més, mentre que la resta del grup, que representa un $80 \%$ ha obtingut uns resultats alterats.

\begin{tabular}{|l|l|l|}
\hline Schimmer normal & Schimmer normal +50\% & Schimmer Alterat \\
\hline De 0 a $3,8 \%$ & De $3,9 \%$ a $5,7 \%$ & A partir de $5,8 \%$ \\
\hline $0 \%$ & $20 \%$ & $80 \%$ \\
\hline 0 persones & 2 persones & 8 persones \\
\hline
\end{tabular}

Taula 20 - Valors de Schimmer dels mestres d'educació primària amb experiència

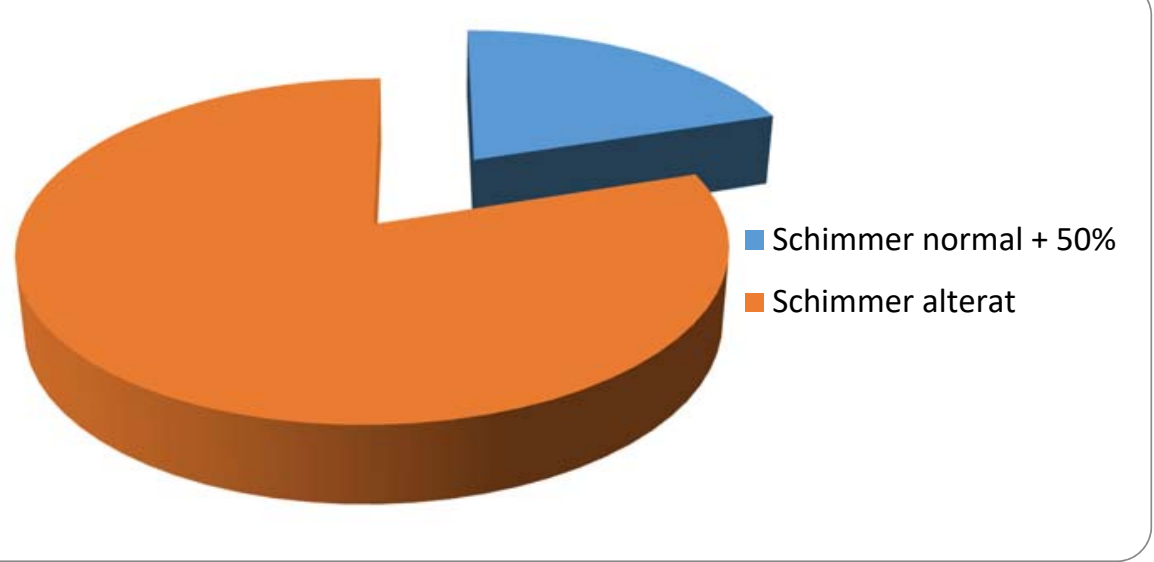

Gràfic 10 - Valors de Schimmer dels mestres d'educació primària amb experiència

El tercer paràmetre valorat per conèixer la qualitat vocal dels mestres analitzats ha estat el HNR. Aquest valor ha donat un resultat força alterat, $15.310 \mathrm{~dB}$, atès que el valor normal es situa al voltant dels $20.00 \mathrm{~dB}$. Cal destacar que 3 subjectes integrants d'aquesta 
mostra $-30 \%$ - han obtingut uns resultat considerats dins la normalitat respecte del valor standard, mentre que la resta del grup, que representa un $70 \%$, ha obtingut uns resultats alterats.

\begin{tabular}{|l|l|}
\hline $\begin{array}{l}\text { HNR normal } \\
\text { proper a l'entorn de } 20 \mathrm{~dB} \text { o més }\end{array}$ & $\begin{array}{l}\text { HNR alterat } \\
\text { de } 0 \mathrm{~dB} \text { fins l'entorn de } 20 \mathrm{~dB}\end{array}$ \\
\hline $30 \%$ & $70 \%$ \\
\hline 3 persones & 7 persones \\
\hline
\end{tabular}

Taula 21 - Valors de HNR dels mestres d'educació primària amb experiència

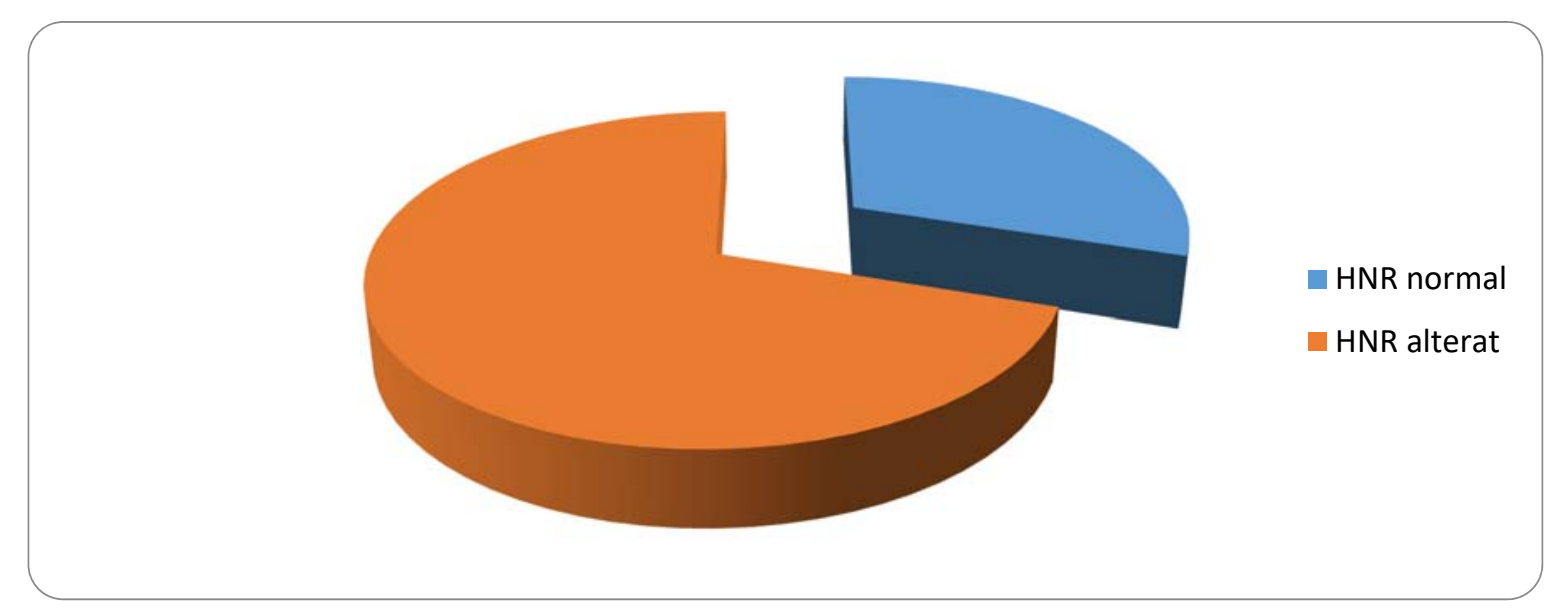

Gràfic 11 - Valors de HNR dels mestres d'educació primària amb experiència

\subsubsection{Mestres d’Educació Física}

En el cas dels mestres d'educació física, val a dir que pel que fa al primer paràmetre de la veu analitzat, Jitter, el valor mitjà resultant d'aquets informants ha estat de $0.403 \%$, valor que es situa dins el valors standards de normalitat establerts, per tant, en aquest cas el $100 \%$ de la mostra ha obtingut resultats dins de la normalitat.

D'altra banda, els resultats del segon paràmetre analitzat, Schimmer, presenta un valor mitjà global de $7.063 \%$ valor que es situa fora dels valors standards de normalitat establerts (3.810\%). Tot i això, cal destacar que 4 subjectes integrants d'aquesta mostra $40 \%$ - han obtingut resultats dins la normalitat respecte del valor standard $(3.810 \%)$ o el $50 \%$ més, mentre que la resta del grup, que representa un $60 \%$ ha obtingut uns resultats alterats.

\begin{tabular}{|l|l|l|}
\hline Schimmer normal & Schimmer normal + 50\% & Schimmer Alterat \\
\hline De 0 a $3,8 \%$ & De $3,9 \%$ a $5,7 \%$ & A partir de $5,8 \%$ \\
\hline $20 \%$ & $20 \%$ & $60 \%$ \\
\hline 2 persones & 2 persones & 6 persones \\
\hline
\end{tabular}

Taula 22 - Valors de Schimmer dels mestres d'educació física 


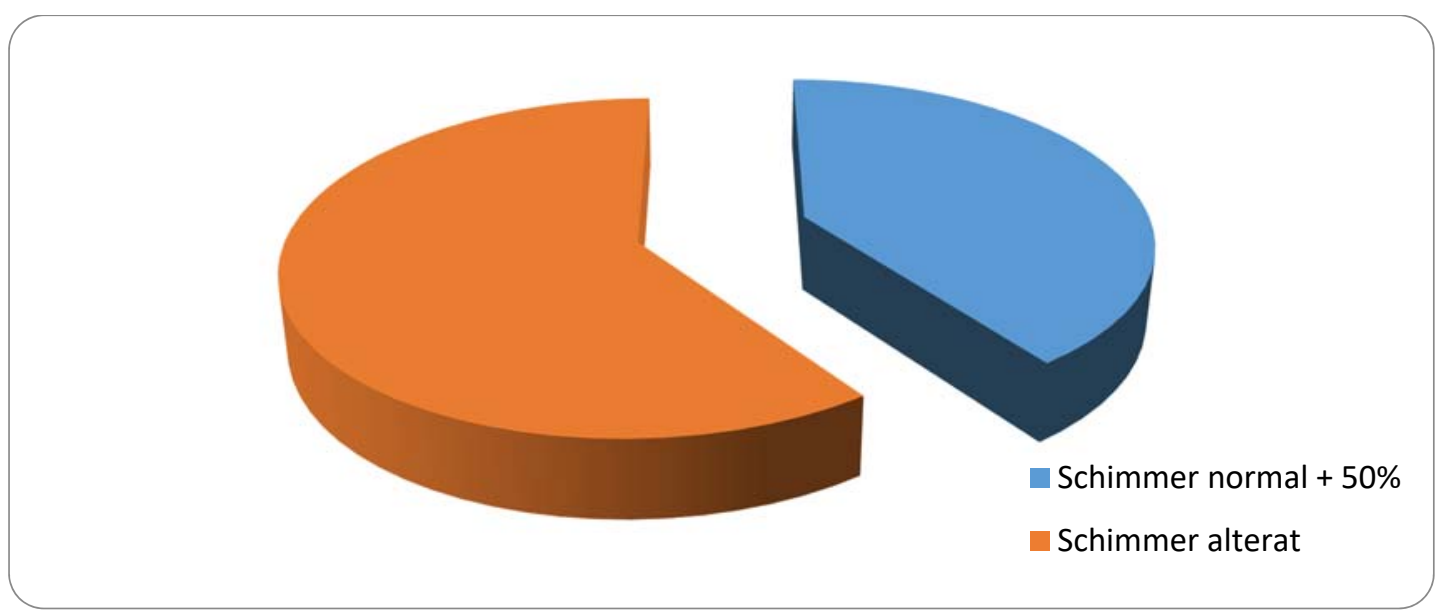

Gràfic 12 - Valors de Schimmer dels mestres d'educació física

El tercer paràmetre valorat per conèixer la qualitat vocal dels mestres analitzats ha estat el HNR. Aquest valor ha donat un resultat força alterat, $15.650 \mathrm{~dB}$, atès que el valor normal es situa al voltant dels $20.00 \mathrm{~dB}$. Cal destacar que 2 subjectes integrants d'aquesta mostra $-20 \%$ - han obtingut uns resultat considerats dins la normalitat respecte del valor standard, mentre que la resta del grup, que representa un $80 \%$, ha obtingut uns resultats alterats.

\begin{tabular}{|l|l|}
\hline $\begin{array}{l}\text { HNR } \\
\text { normal } \\
\text { proper a l'entorn de } 20 \mathrm{~dB} \text { o més }\end{array}$ & $\begin{array}{l}\text { HNR } \\
\text { alterat } \\
\text { de } 0 \mathrm{~dB} \text { fins l'entorn de } 20 \mathrm{~dB}\end{array}$ \\
\hline $20 \%$ & $80 \%$ \\
\hline 2 persones & 8 persones \\
\hline
\end{tabular}

Taula 23 - Valors de HNR dels mestres d'educació física

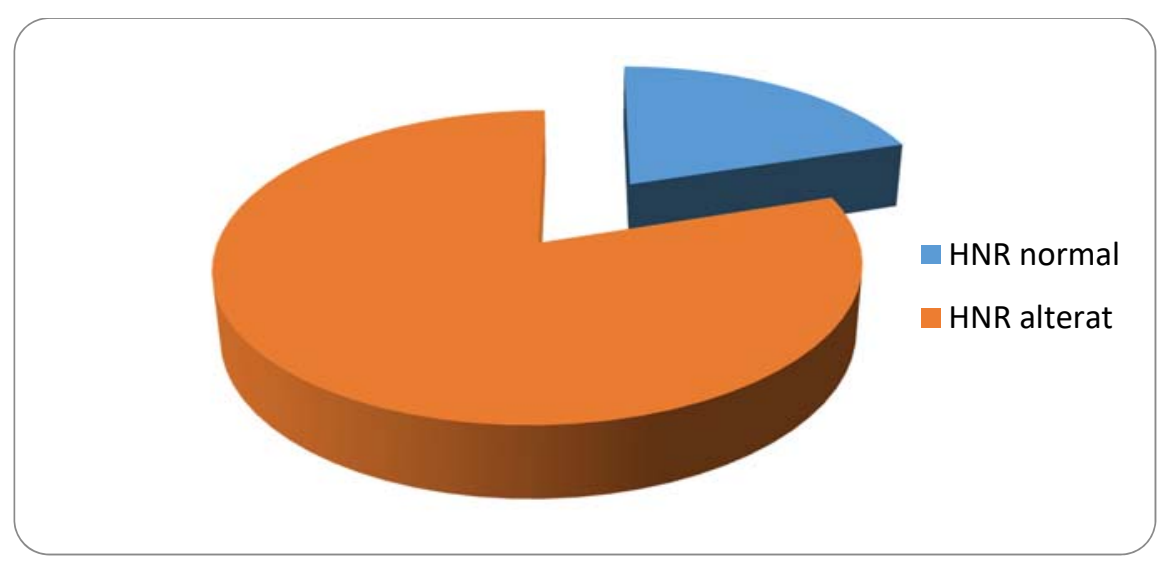

Gràfic 13 - Valors de HNR dels mestres d'educació física

\subsubsection{Mestres de Llengües Estrangeres}

En el cas dels mestres de llengües estrangeres, val a dir que pel que fa al primer paràmetre de la veu analitzat, Jitter, el valor mitjà resultant d'aquets informants ha estat de $0.713 \%$, valor que es situa dins el valors standards de normalitat establerts. Tot i que cal destacar que un subjecte integrant d'aquesta mostra $-10 \%$ - ha obtingut un resultat alterat respecte del valor standard (1.040\%), la resta del grup, que representa un $90 \%$ ha obtingut uns resultats dins de la normalitat. 
D'altra banda, els resultats del segon paràmetre analitzat, Schimmer, presenta un valor mitjà global de $10.974 \%$ valor que es situa fora dels valors standards de normalitat establerts $(3.810 \%)$. Tot i això, cal destacar que 1 subjecte integrant d'aquesta mostra $10 \%$ - ha obtingut un resultat dins la normalitat respecte del valor standard (3.810\%) o el $50 \%$ més, mentre que la resta del grup, que representa un $90 \%$ ha obtingut uns resultats alterats.

\begin{tabular}{|l|l|l|}
\hline Schimmer normal & Schimmer normal + 50\% & Schimmer Alterat \\
\hline De 0 a $3,8 \%$ & De $3,9 \%$ a $5,4 \%$ & A partir de $5,5 \%$ \\
\hline $0 \%$ & $10 \%$ & $90 \%$ \\
\hline 0 persones & 1 persona & 9 persones \\
\hline
\end{tabular}

Taula 24 - Valors de Schimmer dels mestres de llengües estrangeres

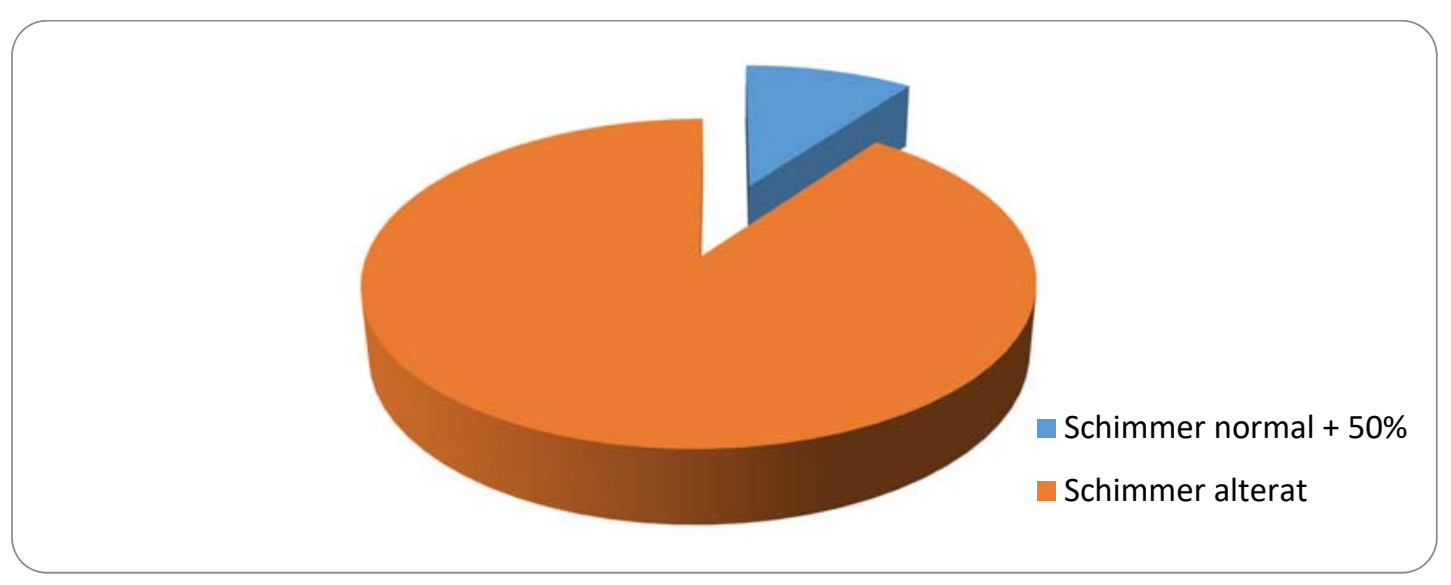

Gràfic 14 - Valors de Schimmer dels mestres de llengües estrangeres

El tercer paràmetre valorat per conèixer la qualitat vocal dels mestres analitzats ha estat el HNR. Aquest valor ha donat un resultat força alterat, $14.784 \mathrm{~dB}$, atès que el valor normal es situa al voltant dels $20.00 \mathrm{~dB}$. Cal destacar que 1 subjecte integrant d'aquesta mostra $-10 \%$ - ha obtingut un resultat considerats dins la normalitat respecte del valor standard, mentre que la resta del grup, que representa un $90 \%$, ha obtingut uns resultats alterats.

\begin{tabular}{|l|l|}
\hline $\begin{array}{l}\text { HNR normal } \\
\text { proper a l'entorn de } 20 \mathrm{~dB} \text { o més }\end{array}$ & $\begin{array}{l}\text { HNR alterat } \\
\text { de } 0 \mathrm{~dB} \text { fins l'entorn de } 20 \mathrm{~dB}\end{array}$ \\
\hline $10 \%$ & $90 \%$ \\
\hline 1 persona & 90 persones \\
\hline
\end{tabular}

Taula 25 - Valors de HNR dels mestres de llengües estrangeres 


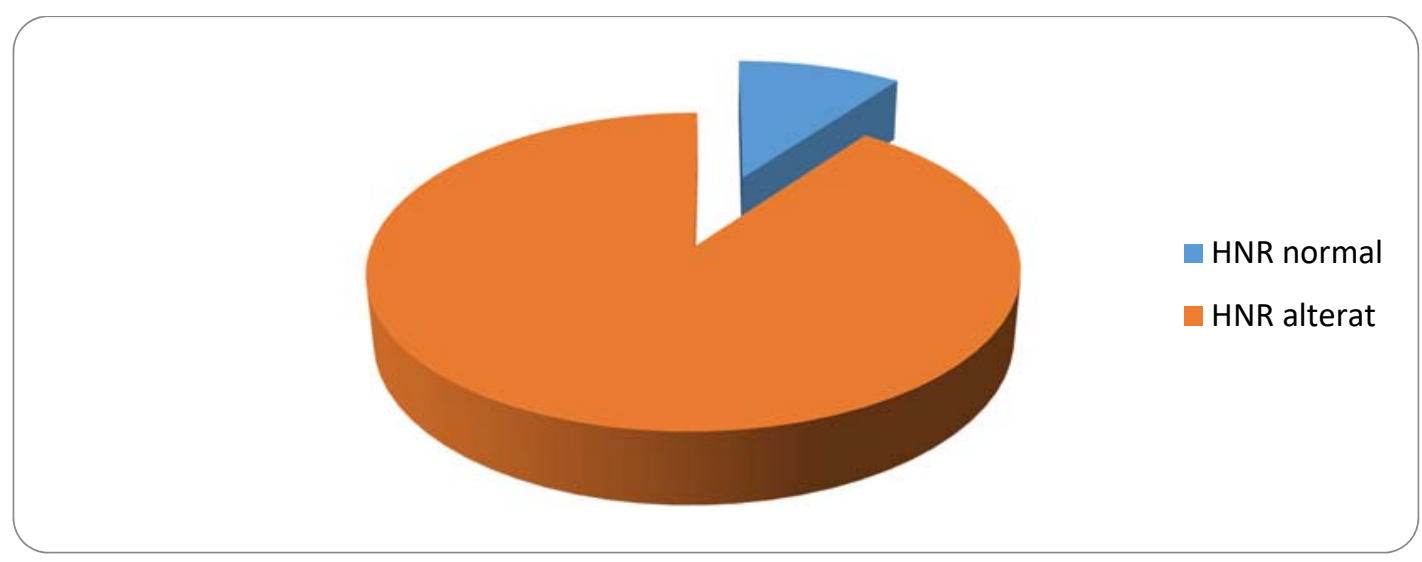

Gràfic 15 - Valors de HNR dels mestres de llengües estrangeres

\subsubsection{Mestres de Música}

En el cas dels mestres de música, val a dir que pel que fa al primer paràmetre de la veu analitzat, Jitter, el valor mitjà resultant d'aquets informants ha estat de $0.279 \%$, valor que es situa dins el valors standards de normalitat establerts, per tant, en aquest cas el $100 \%$ de la mostra ha obtingut resultats dins de la normalitat.

D'altra banda, els resultats del segon paràmetre analitzat, Schimmer, presenta un valor mitjà global de 8,989\% valor que es situa fora dels valors standards de normalitat establerts $(3.810 \%)$, per tant, en aquest cas el $100 \%$ de la mostra ha obtingut resultats alterats.

\begin{tabular}{|l|l|l|}
\hline Schimmer normal & Schimmer normal + 50\% & Schimmer Alterat \\
\hline De 0 a $3,8 \%$ & De $3,9 \%$ a $5,4 \%$ & A partir de5,5\% \\
\hline $0 \%$ & $0 \%$ & $100 \%$ \\
\hline 0 persones & 0 persones & 10 persones \\
\hline
\end{tabular}

Taula 26 - Valors de Schimmer dels mestres de música

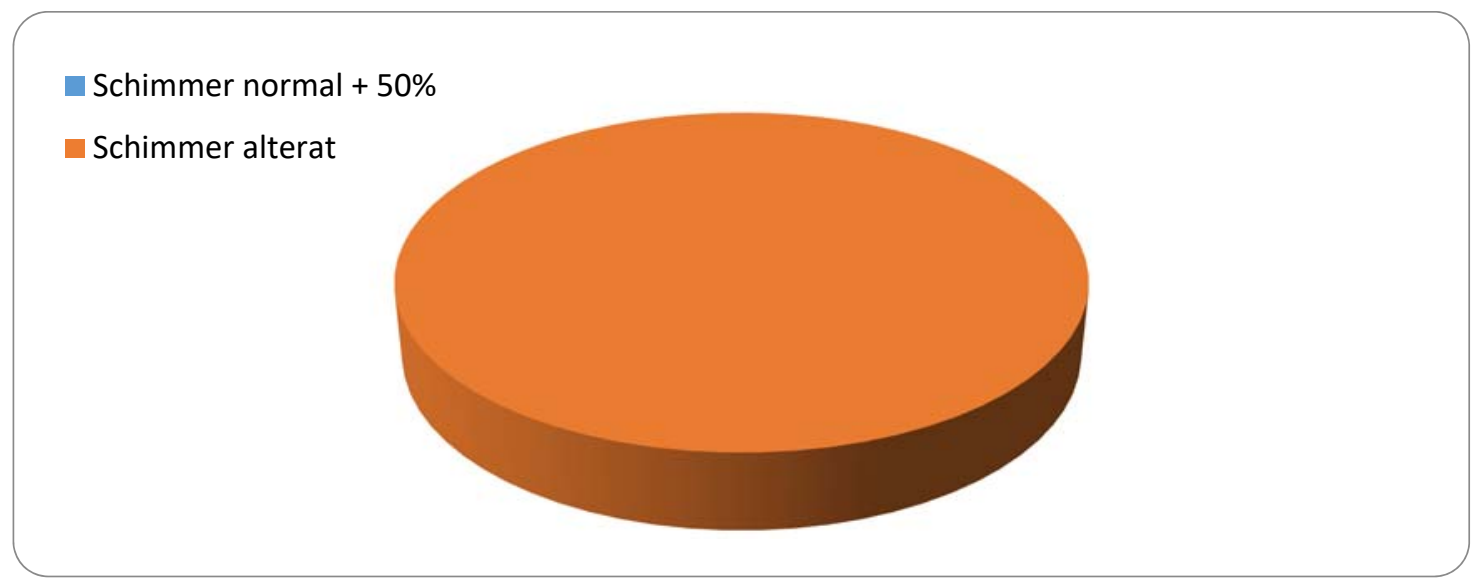

\section{Gràfic 16 - Valors de Schimmer dels mestres de música}

El tercer paràmetre valorat per conèixer la qualitat vocal dels mestres analitzats ha estat el HNR. Aquest valor ha donat un resultat força alterat, $17.878 \mathrm{~dB}$, atès que el valor normal es situa al voltant dels $20.00 \mathrm{~dB}$. Cal destacar que 5 subjectes integrants d'aquesta mostra $-50 \%$ - han obtingut uns resultat considerats dins la normalitat respecte del valor 
standard, mentre que la resta del grup, que representa un 50\%, ha obtingut uns resultats alterats.

\begin{tabular}{|l|l|}
\hline $\begin{array}{l}\text { HNR normal } \\
\text { proper a l'entorn de } 20 \mathrm{~dB} \text { o més }\end{array}$ & $\begin{array}{l}\text { HNR alterat } \\
\text { de } 0 \mathrm{~dB} \text { fins l'entorn de } 20 \mathrm{~dB}\end{array}$ \\
\hline $50 \%$ & $50 \%$ \\
\hline 5 persones & 5 persones \\
\hline
\end{tabular}

Taula 27 - Valors de HNR dels mestres de música

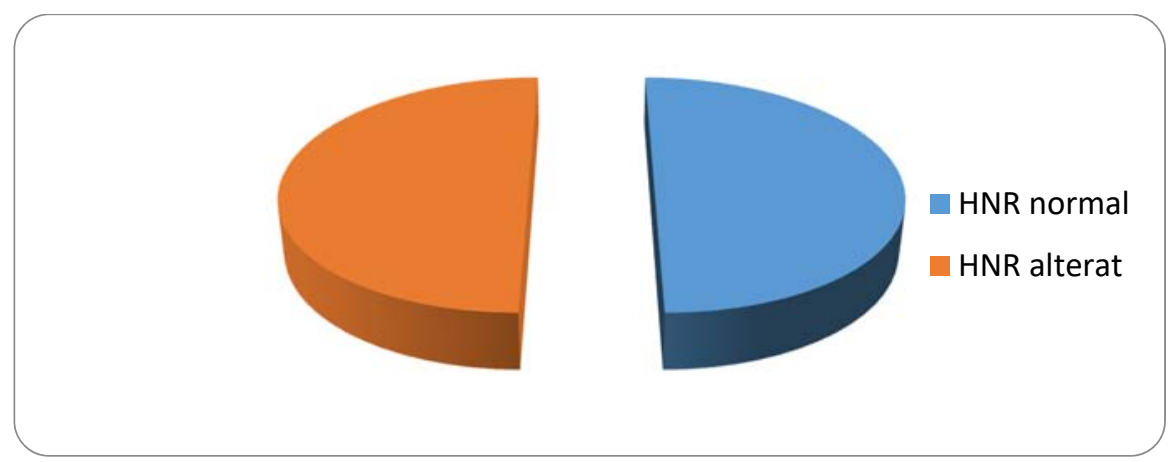

Gràfic 17 - Valors de HNR dels mestres de música

\section{INTERPRETACIÓ DELS RESULTATS}

Tot seguit ha arribat el moment d'interpretar els resultats obtinguts per la mostra en practicar aquest estudi de qualitat vocal sobre un determinat col·lectiu docent. Així doncs, en primer lloc es durà a terme la interpretació dels resultats per categories de mestres. És a dir, mestres generalistes: els d'educació infantil i els d'educació primària, per continuar seguidament amb els especialistes: els mestres d'educació física, de llengües estrangeres i, per últim, els de música. Finalment es comentarà la interpretació que se'n fa per al conjunt de participants en l'estudi.

\subsection{Interpretació dels resultats per especialitats}

La totalitat de mestres d'educació infantil són els que han presentat, a nivell global, per especialitats els resultats més alterats de tota la mostra, valors què es situen lluny dels valors normatius. Aquest aspecte es pot interpretar considerant que, atès que el seu alumnat no sap llegir, en conseqüència, qualsevol matèria o activitat que es realitzi a l'aula cal fer-la de forma totalment oral, aspecte que els porta a fer servir la veu contínuament. Això no és tot, doncs els mestres d'infantil habitualment fan diverses activitats que suposen un esforç vocal suplementari, el qual influeix directament en l'alteració de la qualitat vocal. Per exemple, el fet d'utilitzar contes com a instrument d'aprenentatge, fent ells mateixos diferents veus, segons els diferents personatges, o també el fet d'ensenyar cançons a la canalla, són aspectes que suposen una sobrecàrrega de la funció vocal.

No obstant, val a dir que en comparar els resultats dels mestres novells amb els dels mestre amb experiència, s'aprecia una clara millora en el cas dels docents veterans, tot $i$ això, els resultats dels mestres amb experiència continuen presentant uns valors per sota dels obtinguts per la resta de grups de la mostra. Aquesta petita millora de la qualitat que 
s'ha produït entre els mestres d'educació infantil, produïda com a conseqüència del pas dels anys, és el que podem anomenar com una adaptació al medi, doncs mentre que els mestres més joves $\mathrm{i}$ amb poca experiència professional presenten una qualitat vocal més baixa, els professionals que porten més anys a les escoles, comparativament, presenten una qualitat vocal superior. L'explicació d'aquest fenomen rau en que al llarg dels anys d'experiència els mestres han aprés a fer servir millor la veu i, sobretot, el que és més important: a saber administra-la millor, tot fent un estalvi.

Els mestres d'educació primària són els que han presentat els resultats més alterats després dels mestres d'educació infantil. En definitiva, s'observa una clara diferència en la qualitat de la veu entre els mestres generalistes i els especialistes, tot i que, tal i com ja es comentarà en interpretar els resultats dels especialistes, aquest suporten unes condicions vocals molt pitjors si els comparem amb els mestres de primària.

Tot i que els resultats de la totalitat dels mestres de primària estan situats fora dels índex de normalitat dels valors estudiats, val a dir que en comparar els resultats dels mestres novells amb els dels mestres amb experiència, s'aprecia un clara millora en el cas dels docents veterans. Tot $\mathrm{i}$ això, aquesta millora de la qualitat, què també s'ha trobat en menys quantitat entre els mestres d'educació infantil, està produïda com a conseqüència del pas dels anys i relacionada directament amb l'experiència.

Si parlem ara dels mestres especialistes, podem afirmar que en general en tots ells, s'observa una clara diferència en la qualitat de la veu en comparar-los amb els mestres generalistes, malgrat aquests suporten unes condicions vocals molt pitjors si els comparem amb els mestres de primària, doncs canvien amb molta més freqüència de grup classe, aspecte que obliga a fer contínuament una adaptació a l'acústica de l'aula; doncs els cal fer un ús extra de la veu. Aquest és el cas dels mestres de música, i també dels mestres d'educació física que de vegades treballen a l'aire lliure, o bé en grans espais: gimnàs, pavellons esportius...

Els mestres d'educació física estan en desavantatge amb la resta de mestres, doncs solen tenir que fer les seves classes en grans espais, llocs on la veu del docent no té com a punt de referència la potencia que li es característica a l'interior de les aules Elgström 2007 (72), aspecte que sens dubte hauria de portar molt més fàcilment a la fatiga i a la degeneració de la qualitat vocal entre els mestres d'aquesta especialitat. Malgrat això, cal considerar que els resultats d'aquest col·lectiu ens sorprenen especialment, doncs són el grup que presenten la millor qualitat vocal de tot l'estudi, tot i que els seus valors tampoc no estan ubicats dins els valors considerats com a normals.

També hem de tenir en compte que els mestres d'educació física no han rebut cap assignatura obligatòria específica. En canvi, pràcticament en tots els centres, els mestres d'educació física, són els que presenten la mitjana més alta de qualitat vocal, tant si ho camparem amb els mestres especialistes dels centres, com si ho fem amb els mestres generalistes de primària o fins i tot amb els d'educació infantil. Aquests resultats els podem interpretar com que la tonificació muscular en ells és molt més elevada, donada l'augment d'activitat esportiva en comparació a la resta de la mostra. Aquest aspecte permet que el mecanisme vocal funcioni en unes condicions més òptimes, per la qual cosa la musculatura de la laringe no ha de un esforç donat que l'aire expirat ja li arriba correctament. 
Pel que fa als mestres de llengües estrangeres, els resultats obtinguts han estat els més alterats dins de les tres especialitats analitzades. Tot i això, presenten una qualitat vocal sensiblement superior als resultat obtinguts per la totalitat de mestres generalistes primària i infantil-. Podem entendre que el fet de impartir la classe majoritàriament fent servir una llengua que no és la materna del mestre, i amb una entonació diferent, que moltes vegades es situa en una tessitura superior, i fer servir a la vegada la llengua catalana porta a una fatiga més gran de la veu.

Pel que fa als resultats obtinguts pels mestres de música, si ho comparem amb els altres mestres especialistes que es troben a l'escola primària, s'observa que no tenen una qualitat vocal molt superior a la de les demés especialitats, tot i que al llarg de la formació com a mestres en educació musical han rebut una assignatura de curs obligatori "Formació vocal i Auditiva", matèria que en algunes universitats catalanes pot ser, a més a més, complementada amb assignatura optatives o de lliure elecció que treballen diferents aspectes de la veu a l'aula.

Tot i això, és important considerar que els mestres de música, en canvi, haurien de tenir una qualitat vocal molt millor, doncs a més d'haver rebut una formació vocal específica en el transcurs del estudis de magisteri no podem oblidar que son els encarregats de fer cantar als infants i per això, tal i com diu Elgström (2005) han de vetllar per aconseguir, tot fent ús dels mecanismes adients, una emissió de la veu natural que, en cantar, els permeti presentar als infants un bon exemple vocal mitjançant una veu agradable, ben impostada, ben afinada i amb una pronúncia correcta; exemple vocal que, sens cap mena de dubte, sempre serà la millor explicació i alhora el millor mestratge.

\section{2.- Interpretació dels resultats globals}

Referint-nos als resultats obtinguts a nivell global, podem dir que tant sols hi ha un 7,1\% de la mostra que han presentat els valors de Schimmer i HNR dins dels valors que habitualment es prenen com a normatius, mentre que la majoria, el 92,9\% de veus, presenten una alteració en ambdós paràmetres. Per això, en aquest cas la única interpretació possible de les dades obtingudes és afirmar que el nivell de qualitat vocal dels mestres de Castelldefels es troba força lluny del que caldria.

\section{CONCLUSIONS}

Després d'haver analitzat els paràmetres indicatius del nivell de qualitat de veu dels docents, en cadascuna de les veus dels mestres que han participat en el present estudi, s'ha pogut comprovar que els resultats obtinguts s'allunyen força dels valors considerats com a normatius i, per tant, es pot afirmar, des d'un punt de vista totalment objectiu, que la gran majoria de mestres analitzats no disposen, actualment, d'una veu en un grau de qualitat vocal òptim que els permeti desenvolupar la seva tasca docent.

En resum, i pel que fa als resultats globals de l'estudi, podem dir que les xifres resultants són força preocupants, doncs dels dos paràmetres que realment tenen una relació directa per conèixer el grau de qualitat vocal, el Schimmer i el HNR, els quals determinen el grau de disfonia de la veu i, al mateix temps de qualitat vocal; els dos paràmetres donen un valor mitjà situat fóra dels nivells recomanats.

En conseqüència, podem parlar d'una clara presència de problemes de veu i de disfonia entre el col-lectiu docent que ha conformat la mostra d'aquesta recerca, els mestres de 
les escoles públiques de la població de Castelldefels, aspecte que s'esdevé especialment preocupant pel fet de tractar-se de professionals de la veu. I per tant, no podem oblidar que els mestres són diàriament un exemple de veu parlada i cantada pels seus alumnes, sobretot per a l'alumnat d'educació infantil i els primers cursos de primària, els quals copien els models presentats pels docents; aspecte pel qual és imprescindible que les veus dels mestres siguin autènticament un model a imitar.

Atès que el treball realitzat es tracta d'una recerca que pretén conèixer, d'una manera objectiva i mitjançant unes eines adients, l'estat concret de salut vocal -i alhora laboraldels mestres d'educació infantil i primària i els mestres especialistes d'una població en concret, les contribucions al sistema educatiu són diverses.

En primer lloc, es perfila una aportació important de la recerca al sistema educatiu, pel fet de disposar de xifres objectives per tal de conèixer la situació vocal del col·lectiu dels mestres d'una població en concret de la geografia catalana, estudi que fóra ampliable a d'altres poblacions de Catalunya, per tal de saber l'estat de salut vocal actual dels docents.

Pel que fa a aquests resultats, poden alertar a l'administració, la qual llavors pot plantejarse l'organització de cursos de formació vocal per als mestres en exercici, aspecte que pot significar una contribució directa per reduir els problemes de la veu en els docents. En definitiva, contribuir així a la millora de la salut laboral dels mestres, especialment ajudant als docents de nova incorporació en la seva tasca, atès que, tal i com ha quedat plasmat en els resultats d'aquest treball, es traca del sector dels mestres més propens a estar afectat per un baix nivell de qualitat vocal.

En segon lloc, fóra interessant plantejar-se la necessitat imminent de reformar els plans d'estudi de magisteri, tot implantat obligatòriament una assignatura dedicada exclusivament a la formació vocal en totes les especialitats de la carrera. Ara per ara, i llevat de l'especialitat de mestre en educació musical en què es rep una formació específica dirigida a l'ús de la veu, que pel que s'ha observat en aquest estudi tampoc és del tot satisfactòria; en totes les demés especialitats no s'inclou cap assignatura.

\section{9.-REFERÈNCIES BIBLIOGRÀFIQUES}

Aguinaga, I. (1988): Las alteraciones faringolaríngeas en el profesorado de E.G.B. de Pamplona. Tesis doctoral. Facultad de Medicina, Universidad de Navarra.

Amir, O.; Wolf, M. i Amir, N. (2008): A clinical comparison between two acoustic analysis softwares: MDVP and Praat. Biomedical Signal Processing and Control.

Aronson, A. (1985): Clinical voice disorders. An interdisciplinary approach. New York. Thieme Inc.

Bustos, I. (2000): Trastornos de la voz en edad escolar. Archidona: Aljibe.

De Saint-Exupéry, A. (1967): El Petit Princep. Barcelona: Estela

Deliyski, D. (1993): "Acoustic model and evaluation of pathological voice production", a Acta 3-rd Conference on Speech Communication and Technology EUROSPEECH'93, Berlin, Germany, pp.1969-1972.

Elgström, E. (2005): Adequació del camp vocal dels mestres de música. Tesi Doctoral: Dep. de Didàctica de l'Expressió Musical i Corporal de la Univ. de Barcelona. 
Elgström, E. (2007): “La formació vocal: una matèria pendent en els estudis de Magisteri a l'estat espanyol". Revista Guix, 332, 71-83.

Elgström, E. (2009): “L'educació vocal en la formació inicial dels docents a l'estat espanyol: descripció de la situació actual i propostes per generar un canvi”. Revista Temps d'Educació.

Fiuza, M. J. (1995): Las disfonías disfuncionales en los maestros de la comunidad autónoma de Galicia. Tesis doctoral. Facultad de Psicología, Universidad de Santiago de Compostela.

Jackson-Menaldi, M.C.A. (2002): "Patología vocal y su reeducación”, a JacksonMenaldi, M.C.A. (coord.): La voz patológica (245-266). Buenos Aires: Editorial Médica Panamericana.

Muñoz López, J. (1997): Análisis acústico y perceptivo de la voz: valores normativos y alteraciones en la voz patológica. Tesis doctoral. Facultad de Psicología, Universidad de Granada.

Piñero, I. i Pire de Bastidas, B. (2002): “Análisis acústico de la voz en pacientes con disfonía funcional, antes y después de la terapia”. Servicio de foniatría Hospital Central Antonio María Pineda, a "Boletin Médico de Postgrado" Vol. XVIII, número 1 enero UCLA. Decanato de Medicina Barquisimetro, Venezuela.

Preciado, J.; Pérez, P.; Calzada, M. i Preciado, P. (2005): "Examen de la función vocal y análisis acústico de 905 docentes de La Rioja", a Acta de la Sociedad española de otorrinolaringología y patología cérvico-facial, vol 56, p261-272. Madrid: Saned.

Puyuelo, M i Llinás, M. A. (1992): "Problemas de voz en docentes" a Revista de Logopedia, Foniatría y Audiología, XII, 2, 76-84.

Urrutikoetxea, A.; Ispizua, A; Matellanes, F. (1995): "Pathologie vocals chez les professeurs: un etude video-laryngo-stroboscopique de 1046 professeurs". Rev. Laryngol Otol Rhinol,116:255-262.18.

Wolf, V.; Fith, J.; Cornell, R. (1995): “Acoustic Prediction of Severity in commonly occurring voice problems”. Journal Speech Hear Res April 38 (2) 273-279. 